\title{
A Comparison between 3DVAR and EnKF for Data Assimilation Effects on the Yellow Sea Fog Forecast
}

\author{
Xiaoyu Gao (anthas@126.com) \\ Shanhong Gao*(gaosh@ouc.edu.cn) \\ Yue Yang (yangyueouc@163.com)
}

Key Laboratory of Physical Oceanography, College of Oceanic and Atmospheric Sciences, Ocean University of China, Qingdao 266100, China

${ }^{*}$ Corresponding author address: Shanhong Gao, Key Laboratory of Physical Oceanography, College of Oceanic and Atmospheric Sciences, Ocean University of China, 5 Yushan Road, Qingdao 266003, China

Email: gaosh@ouc.edu.cn

\begin{abstract}
The data assimilation method to improve sea fog forecast over the Yellow Sea is usually threedimensional variational assimilation (3DVAR), whereas ensemble Kalman filter (EnKF) has not yet been applied on this weather phenomenon. In this paper, two sea fog cases over the Yellow sea, one spread widely and the other spread narrowly along the coastal area, are studied in detail by a series of numerical experiments with 3DVAR and EnKF based on the Grid-point Statistical Interpolation (GSI) system and the Weather Research and Forecasting (WRF) model. The results show that the assimilation effect of EnKF outperforms that of 3DVAR: for the widespread-fog case, the probability of detection and equitable threat scores of the forecasted sea fog area get improved respectively by $\sim 57.9 \%$ and $\sim 55.5 \%$; the sea fog of the other case completely mis-forecasted by $3 \mathrm{DVAR}$ is produced successfully by EnKF. These improvements of EnKF relative to 3DVAR are benefited from its
\end{abstract}


flow-dependent background error, resulting in more realistic depiction of sea surface wind for the widespread-fog case and better moisture distribution for the other case in the initial conditions. More importantly, the correlation between temperature and humidity in the background error of EnKF plays a vital role in the response of moisture to the assimilation of temperature, which leads to a great improvement on the initial moisture conditions for sea fog forecast.

Keywords: sea fog; data assimilation; 3DVAR; EnKF

\section{Introduction}

Sea fog usually refers to the fog that occurs over the ocean or a coastal region (Wang, 1985; Koračin and Dorman, 2017). It causes atmospheric horizontal visibility less than $1 \mathrm{~km}$ and even to tens of meters, which has a serious effect on harbor activities and marine transport. Among the seas of China, the Yellow Sea experiences a high frequency of sea fog (Gao et.al, 2007; Zhang et al., 2009). Numerical modeling is already becoming the major approach to both investigating formation mechanism and developing forecast method for the Yellow Sea fog (Wang et al., 2014; Fu et al., 2016).

Previous studies have revealed that the sea fog simulation is extremely sensitive to the errors of initial conditions (Nicholls 1984; Findlater et al. 1989; Ballard et al. 1991; Lewis et al., 2003; Koračin et al., 2001, 2005a, b; Fu et al., 2006; Gao et al., 2007, 2010). Therefore, it is very necessary to provide better initial conditions for sea fog simulation as possible as we can via data assimilation. The sea fog simulation result can be improved to some extent by assimilating a lot of kinds of observations using the three-dimensional variational data assimilation (3DVAR) method based on the Weather Research and Forecasting (WRF) model. These assimilated observations 
include routine measurements along coast of the Yellow Sea (Gao et al., 2010), sea surface wind data aboard QuikSCAT (Quick Scatterometer; Liu et al., 2011), satellite radiance (Li et al., 2012), Doppler radar radial velocity (Wang and Gao, 2016) as well as temperature and moisture profiles derived from satellites (Wang et al., 2017). Due to a lack of routine observations over sea, a new method was proposed by Wang et al. (2014) to assimilate satellite-derived humidity from the observed sea fog over the Yellow Sea, which improves the sea fog nowcasting skill with the increase of equitable threat scores (ETS) ranging from $15 \%$ to $20 \%$.

However, due to the employment of static background error covariances, there is a weakness in the 3DVAR method that the above studies feature essentially. The NMC (National Meteorological Center) method (Parrish and Derber, 1992) is generally used to generate this background error covariances using forecast differences. As pointed out by Bouttier (1994), the NMC method is suitable only for estimation of climatological covariances. Because forecast differences are usually calculated over a reasonably long period of time (e.g., half or a month of forecast differences), the variation of the background error in different synoptic situation from one case to the next is neglected.

The Yellow Sea fog usually forms when water vapor condenses within marine atmospheric boundary layer (Gao et al., 2007) under an appropriate synoptic system (Yang and Gao, 2015). Atmospheric flow near sea surface determined by the synoptic system perhaps play an important role in reasonably spreading observed information during the entire assimilation period (i.e., flowdependent). The limitations of static background error covariances make 3DVAR unable to manifest this flow-dependent feature. The data assimilation (DA) methods, such as Hybrid-3DVAR (Hamill and Snyder, 2000; Wang et al., 2008a, b), 4DVAR (Talagrand and Courtier, 1987; Courtier 
and Talagrand, 1987) and EnKF (Ensemble Kalman Filter; Evensen, 1994), can provide flowdependent background error covariances, and they have been widely employed in simulations of hurricane and typhoon that have strong flow structure (Yuan et al., 2010; Wang et al., 2011; Poterjoy et al., 2014; Shen et al., 2016; Lu et al., 2016). Although sea fog has become a severe marine weather and its influences on marine activities might compete with tropical cyclones (Gultepe et al., 2007), application of these advanced flow-dependent DA methods to sea fog numerical modeling are not yet seen.

The National Centers for Environmental Prediction (NCEP) developed an efficient tool - the Grid-point Statistical Interpolation (GSI)/EnKF system that includes built-in 3DVAR and EnKF (Shao et al., 2016), which provides a strong research approach for DA study in sea fog numerical modeling. The goal of the present study is to explore and compare the assimilation effects of 3DVAR and EnKF in sea fog forecast based on the GSI/EnKF system with the WRF model.

This paper is organized as follows. Section 2 briefly describes the methods of 3DVAR and EnKF. Section 3 shows how sea fog data assimilation and forecast experiments are conducted, including data, study cases, model configurations, design of DA schemes and numerical experiments. In Section 4, results and analysis are presented, and comparison of DA effects between 3DVAR and EnKF are addressed in detail. Finally, summary and conclusions are given in section 5.

\section{Data assimilation algorithms}

\section{$2.13 D V A R$}

Let $\mathbf{x}, \mathbf{x}^{\mathrm{b}}, \mathbf{x}^{\mathrm{a}}$ and $\mathbf{y}$ be the model state at the beginning of the assimilation window, a background or prior estimate of $\mathbf{x}$, analysis of $\mathbf{x}$ and observation, respectively. The cost function for 3DVAR can be defined by 


$$
\mathrm{J}(\mathbf{x})=\mathrm{J}_{\mathrm{b}}+\mathrm{J}_{\mathrm{o}}=\frac{1}{2}\left[\left(\mathbf{x}^{\mathrm{a}}-\mathbf{x}^{\mathrm{b}}\right)^{\mathrm{T}} \mathbf{B}^{-1}\left(\mathbf{x}^{\mathrm{a}}-\mathbf{x}^{\mathrm{b}}\right)+\left(\mathbf{y}-\mathbf{H} \mathbf{x}^{\mathrm{a}}\right)^{\mathrm{T}} \mathbf{R}^{-1}\left(\mathbf{y}-\mathbf{H} \mathbf{x}^{\mathrm{a}}\right)\right]
$$

where $\mathbf{H}$ is the observation operator matrix which transforms data from model space to observation space, $\mathbf{R}$ is the observation error covariance matrix, and $\mathbf{B}$ is the background error covariance matrix. By using the increment formulation (Courtier et al., 1994), the analysis increment and observation innovation are respectively defined as $\delta \mathbf{x}=\mathbf{x}^{\mathrm{a}}-\mathbf{x}^{\mathrm{b}}$ and $\mathbf{d}=\mathbf{y}-\mathbf{H} \mathbf{x}^{\mathrm{b}}$. Thus, Eq. 1 can be rewritten

$$
\mathrm{J}(\mathbf{x})=\frac{1}{2}\left[\delta \mathbf{x}^{\mathrm{T}} \mathbf{B}^{-1} \delta \mathbf{x}+(\mathbf{H} \delta \mathbf{x}-\mathbf{d})^{\mathrm{T}} \mathbf{R}^{-1}(\mathbf{H} \delta \mathbf{x}-\mathbf{d})\right]
$$

The 3DVAR procedure in the GSI/EnKF system calculates $\mathbf{x}^{\mathrm{a}}$ by minimizing Eq. 2 with iterative solution method (Shao et al., 2016).

$\mathbf{H}$ and $\mathbf{R}$ can be priorly determined, while $\mathbf{B}$ needs to be calculated by statistics. The NMC method is used here to generate $\mathbf{B}$ as follows

$$
\mathbf{B} \approx \frac{1}{\mathrm{~T}_{\mathrm{n}}-1} \sum_{\mathrm{t}=1}^{\mathrm{T}_{\mathrm{n}}}\left(\mathbf{x}_{\mathrm{t}}^{12 \mathrm{~h}}-\mathbf{x}_{\mathrm{t}}^{24 \mathrm{~h}}\right)\left(\mathbf{x}_{\mathrm{t}}^{12 \mathrm{~h}}-\mathbf{x}_{\mathrm{t}}^{24 \mathrm{~h}}\right)^{\mathrm{T}}
$$

where $\mathbf{x}_{\mathrm{t}}^{12 \mathrm{~h}}$ and $\mathbf{x}_{\mathrm{t}}^{24 \mathrm{~h}}$ are respectively $12 \mathrm{~h}$ and $24 \mathrm{~h}$ model forecasts at the time of $\mathrm{t}$, and $\mathrm{T}_{\mathrm{n}}$ is the time period for statistics, which is usually 15-30 days. The WRF model has $\mathrm{N}\left(\sim 10^{7}\right)$ degrees of freedom, thus directly solving the inversion of $\mathbf{B}$ (i. e., $\left.\mathbf{B}^{-1}\right)$ requires $\sim \mathrm{O}\left(10^{14}\right)$ times of calculations, which is technically impossible. However, B is usually diagonalized by control variable transform, which uses length scale coefficients to store the correlations between different grids and regression coefficients to store the correlations between different variables. Note that these coefficients are regional averaged for decreasing the computational cost and $\mathbf{B}$ is therefore static and nearly homogeneous and isotropic.

\subsection{EnKF}

The background error covariance that is represented by the matrix $\mathbf{P}^{\mathrm{b}}$ in EnKF, is calculated 
using ensemble forecast members. Each ensemble member and Kalman gain matrix are respectively updated by

$$
\begin{gathered}
\mathbf{x}_{\mathrm{i}}^{\mathrm{a}}=\mathbf{x}_{\mathrm{i}}^{\mathrm{b}}+\mathbf{K}\left(\mathbf{y}_{\mathrm{i}}-\mathbf{H} \mathbf{x}_{\mathrm{i}}^{\mathrm{b}}\right) \\
\mathbf{K}=\mathbf{P}^{\mathrm{b}} \mathbf{H}^{\mathrm{T}}\left(\mathbf{R}+\mathbf{H} \mathbf{P}^{\mathrm{b}} \mathbf{H}^{\mathrm{T}}\right)^{-1}
\end{gathered}
$$

where $\mathbf{R}$ and $\mathbf{H}$ are the same as in Eq. 1, $\mathbf{x}_{\mathbf{i}}^{\mathrm{b}}$ is the $\mathrm{i}^{\text {th }}$ ensemble member (let $\mathrm{m}$ be their total number, so that $i=1,2, \ldots, m), \mathbf{x}_{i}^{a}$ is the $i^{\text {th }}$ updated member, and $\mathbf{y}_{\mathrm{i}}$ is the $i^{\text {th }}$ perturbed observation for $\mathbf{x}_{\mathbf{i}}^{\mathrm{b}}$. To avoid calculating the large matrix $\mathbf{P}^{\mathrm{b}}$, EnKF usually proximately calculates $\mathbf{P}^{\mathrm{b}} \mathbf{H}^{\mathrm{T}}$ and $\mathbf{H P}^{\mathrm{b}} \mathbf{H}^{\mathrm{T}}$ as

$$
\begin{gathered}
\mathbf{P}^{\mathrm{b}} \mathbf{H}^{\mathrm{T}} \approx \frac{1}{\mathrm{~m}-1} \sum_{\mathrm{i}=1}^{\mathrm{m}}\left(\mathbf{x}_{\mathrm{i}}^{\mathrm{b}}-\overline{\mathbf{x}^{\mathrm{b}}}\right)\left(\mathbf{H} \mathbf{x}_{\mathrm{i}}^{\mathrm{b}}-\overline{\mathbf{H} \mathbf{x}^{\mathrm{b}}}\right)^{\mathrm{T}} \\
\mathbf{H} \mathbf{P}^{\mathrm{b}} \mathbf{H}^{\mathrm{T}} \approx \frac{1}{\mathrm{~m}-1} \sum_{\mathrm{i}=1}^{\mathrm{m}}\left(\mathbf{H} \mathbf{x}_{\mathrm{i}}^{\mathrm{b}}-\overline{\mathbf{H} \mathbf{x}^{\mathrm{b}}}\right)\left(\mathbf{H} \mathbf{x}_{\mathrm{i}}^{\mathrm{b}}-\overline{\mathbf{H} \mathbf{x}^{\mathrm{b}}}\right)^{\mathrm{T}}
\end{gathered}
$$

Whitaker and Hamill (2002) found that the introduction of observation perturbation to update ensemble members leads to an underestimate of the analysis error, and they proposed the EnSRF (Ensemble Square Root Filter) method to rectify this underestimation. The EnSRF method is adopted by GSI/EnKF system, and it is chosen to use in this paper.

EnKF sequentially assimilates each observation, and treats the analysis updated by one observation as the background for the next assimilation. As a result, $\mathbf{y}, \mathbf{R}$ and $\mathbf{H} \mathbf{P}^{\mathrm{b}} \mathbf{H}^{\mathrm{T}}$ become to be scalers, and $\mathbf{P}^{\mathrm{b}} \mathbf{H}^{\mathrm{T}}$ is reduced to a vector. It brings the benefits that not only avoids matrix inversion but also no need to simplify background error covariances (e.g., diagonalizing), which results in intact correlations between physical variables. Since $\mathbf{P}^{\mathrm{b}} \mathbf{H}^{\mathrm{T}}$ is updated along with assimilating observations, it means the background error covariances may vary substantially depending on the flow of the day (i.e., so-called flow-dependent). 


\section{Numerical experiments}

\subsection{Data}

The synoptic charts were from KMA (Korea Meteorological Administration), and the observed fog area were retrieved empirically from the infrared, albedo and visible cloud imageries of MTSAT (the Multifunctional Transport Satellite; http://weather.is.kochi-u.ac.jp/sat/GAME) using the method by Wang et al. (2014).

The initial and lateral boundary conditions for the WRF simulation later were derived from the NCEP Final Analysis (FNL; $1^{\circ} \times 1^{\circ}, 6$ hourly; https://rda.ucar.edu/datasets/ds083.2), and the sea surface temperature (SST) data were extracted from daily NEAR-GOOS (North-East Asian Regional Global Ocean Observing System) dataset (http://ds.data.jma.go.jp/gmd/goos/data). Observations for data assimilation include radiosonde and surface measurements, satellite-retrieved sea surface winds, and radiation brightness temperatures from AMSU-A/B (Advanced Microwave Sounding Unit A/B), HIRS-3/4 (High Resolution Infrared Radiation Sounder 3/4) and MHS (Microwave Humidity Sounder) carried by satellites (https://rda.ucar.edu/datasets/ds735.0).

Besides radiosonde and surface measurements mentioned above, CCMP (the Cross Calibrated Multi-Platform) global surface wind data (http://www.remss.com/measurements/ccmp) and NCEP ship observations in prepBUFR format (https://rda.ucar.edu/datasets/ds337.0) were used for evaluation.

\subsection{Sea fog cases}

Two typical advection sea fog cases over the Yellow Sea, one spread widely over the Yellow Sea and the other spread narrowly along the Shandong Peninsula coast (Fig. 1), were chosen for study in detail. They happened on 10 Apr 2009 and 02 Apr 2014 (hereafter C-09 and C-14), 
respectively. Although both the two cases were dominated by a high-pressure system (Figs. 1a and 1c), they have obvious differences. In the case $\mathrm{C}-09$, the widespread fog area was formed as warm moist air moved onto a cold sea area (see the SST in Fig. 2a) due to easterly winds in the south of the high (Fig. 1a). But in the case C-14, weak southerly winds near the center of the high (Fig. 1c) carried warm air from the western Yellow Sea and its neighboring land area northward onto the cool coastal area (see the SST in Fig. 2b) along Shandong Peninsula, resulting in sea fog formation. It is judged from cloud color that the fog patch of the case C-09 is deeper than that of the case C-14 (cf. Fig. 1b and Fig.1d), which might indicate that moisture in the latter is not as enough as the former. Perhaps it is due to their obvious difference between the prevailing flows mentioned above.
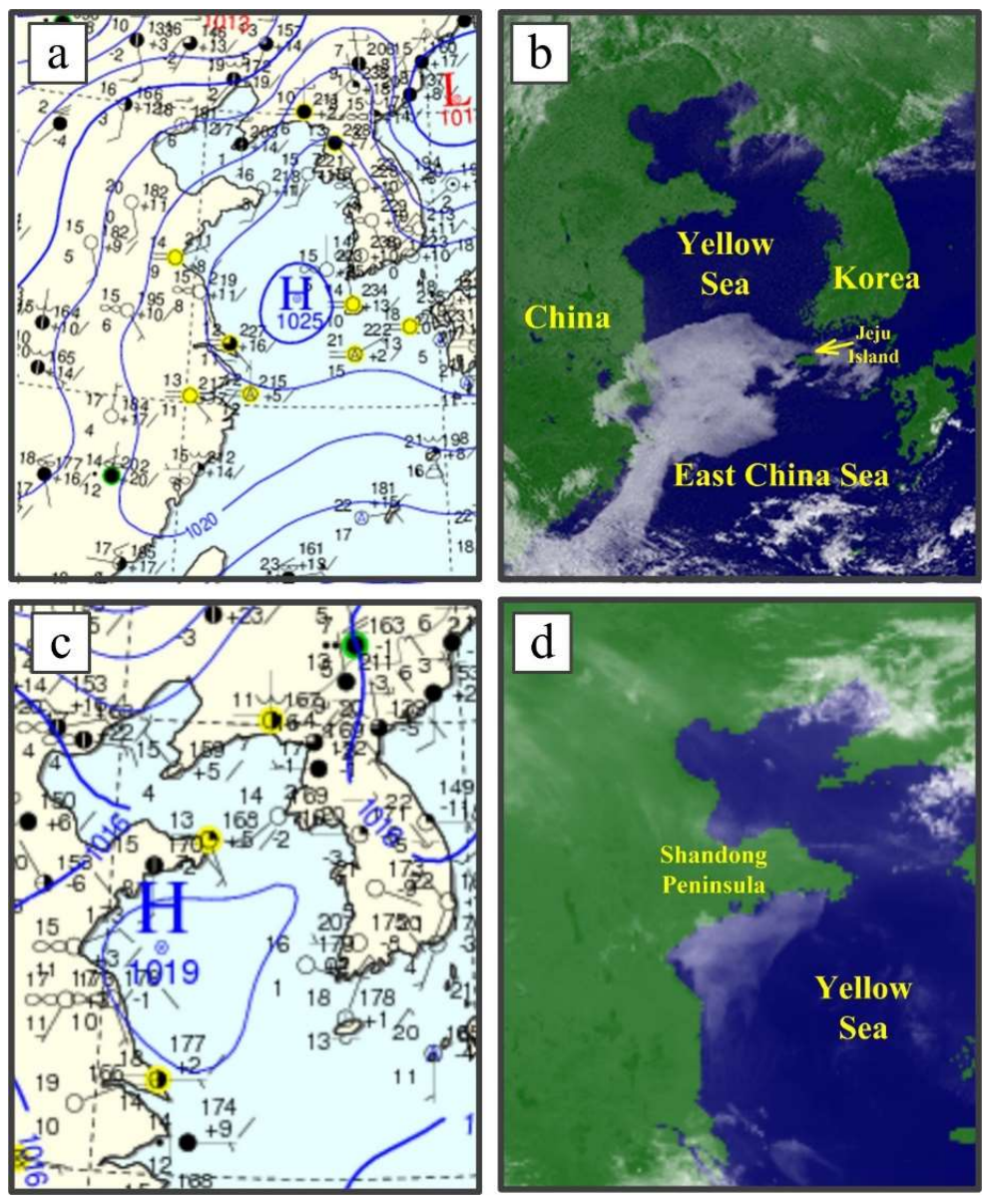

Figure 1. Synoptic surface charts from KMA (left) and MTSAT visible satellite images(right). Upper 
panels are the case C-09 at t at 0000 UTC 10 Apr 2009, and lower panels are for the case C-14 at 0300 UTC 02 Apr 2014.

\subsection{Model configuration}

The Advanced Research core of the WRF (ARW, version 3.8.1; Skamarock et al., 2008) was employed in this study. According to the work of Lu et al. (2014) and Wang et al. (2014), a combination of the planetary boundary layer (PBL) and microphysics schemes YSU-LIN was chosen. The details of model configurations, including domains, horizontal and vertical resolutions, and other physical schemes, are listed in Table 1. Both sea fog cases used 2 domains (D1 and D2) and applied two-way nesting (Fig. 2).

Table 1. WRF configuration.

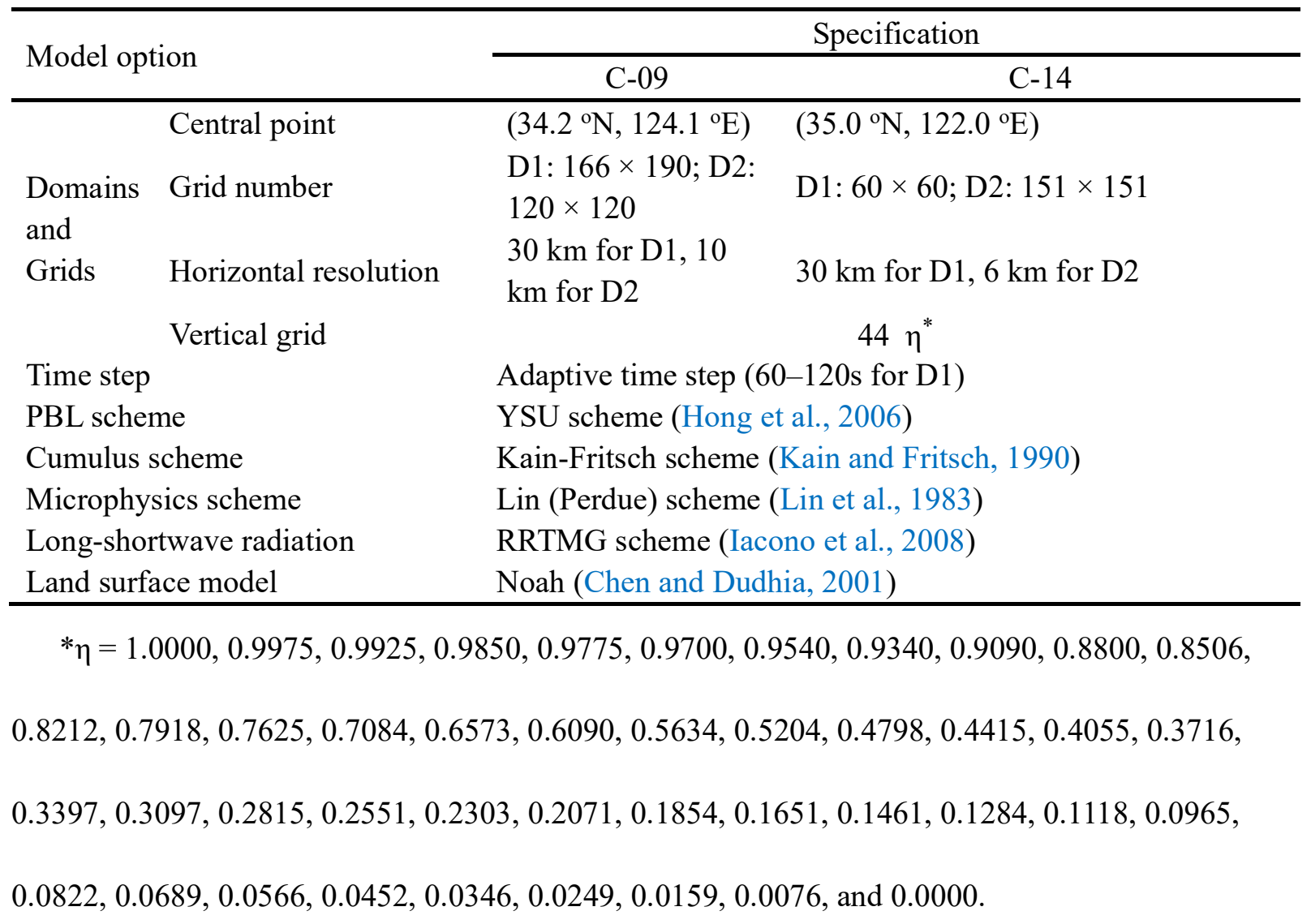



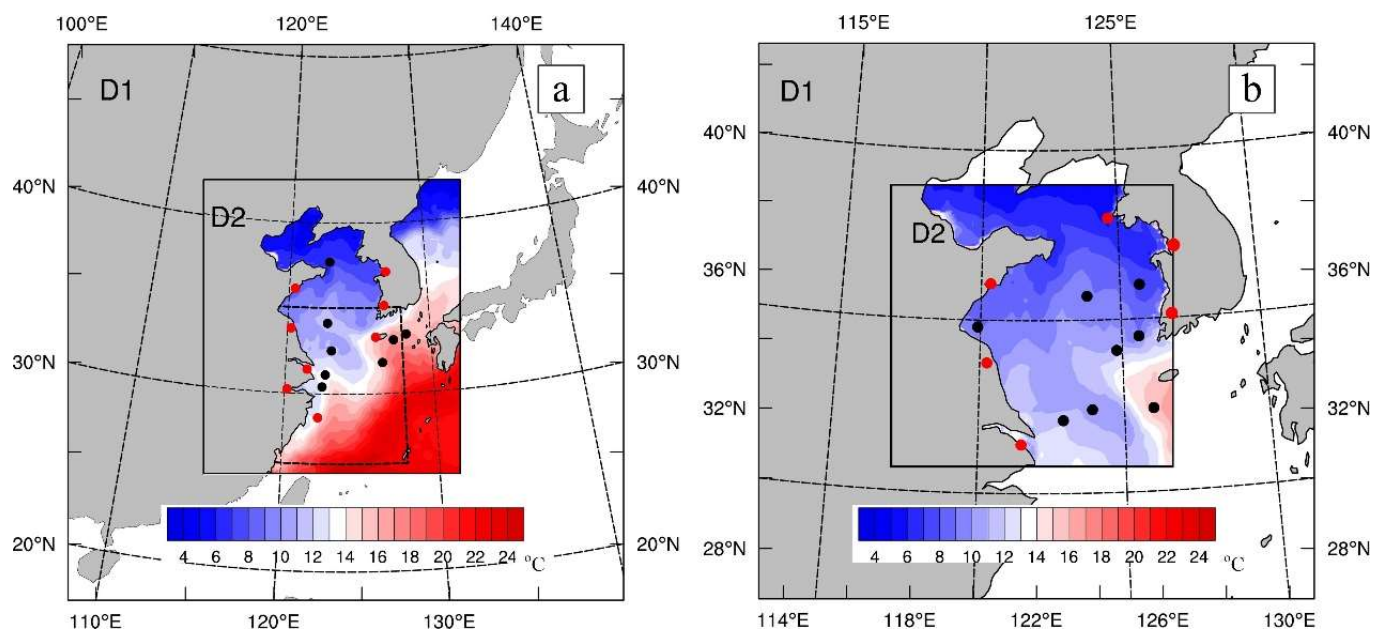

Figure 2. WRF Domains for the cases: (a) C-09 and (b) C-14. Colors show SST within the D2 domains, and the red and black dots respectively locate radiosonde stations and ship measurement sites. The sea area surrounded by thick dashed lines and coastlines in D2 of (a) is used for evaluating forecasted sea surface winds later.

\subsection{Design of DA schemes and experiments}

Three DA schemes were designed for comparing the data assimilation effects between 3DVAR and EnKF. Figure 3 shows a schematic illustration of these schemes. DA-1 and DA-3 schemes are cycling WRF-3DVAR scheme and cycling WRF-EnKF, respectively; DA-2 is cycling WRF3DVAR with multi-backgrounds from the WRF ensemble forecast, and its backgrounds at the beginning of the DA window are the same as DA-3. Among the schemes, $\mathbf{B}$ and $\mathbf{P}^{\mathbf{b}}$ represent the background error covariances for 3DVAR and EnKF, respectively, and obs stands for observations; Each assimilation cycle is connected by the WRF integration (i.e., wrf.exe in Fig. 3), and the final assimilation analysis $\mathrm{x}^{\mathbf{a}}$ or $\overline{\mathbf{x}^{\mathrm{a}}}$ are the initial conditions (ICs) for the next WRF forecast. 
$\mathrm{a}$

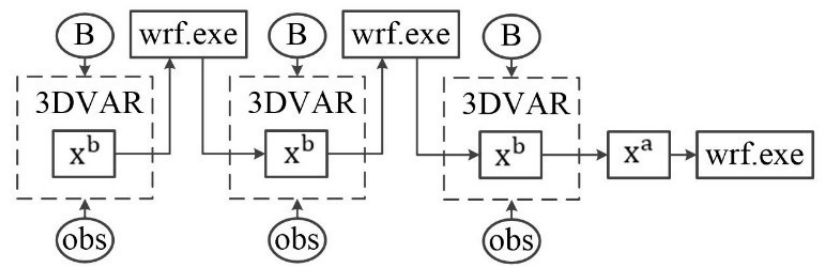

$\mathrm{b}$

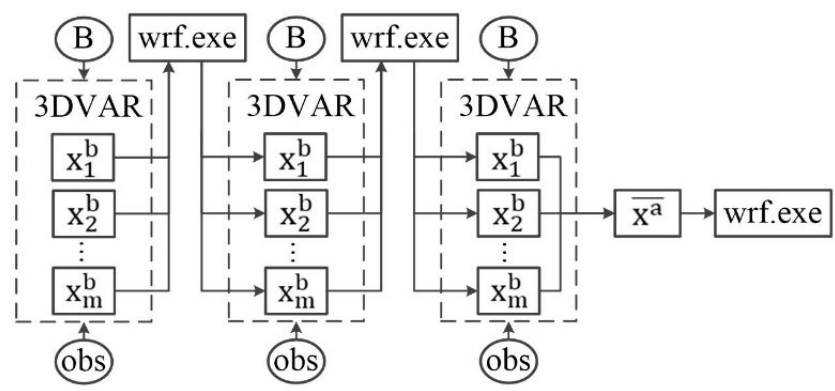

$\mathrm{c}$

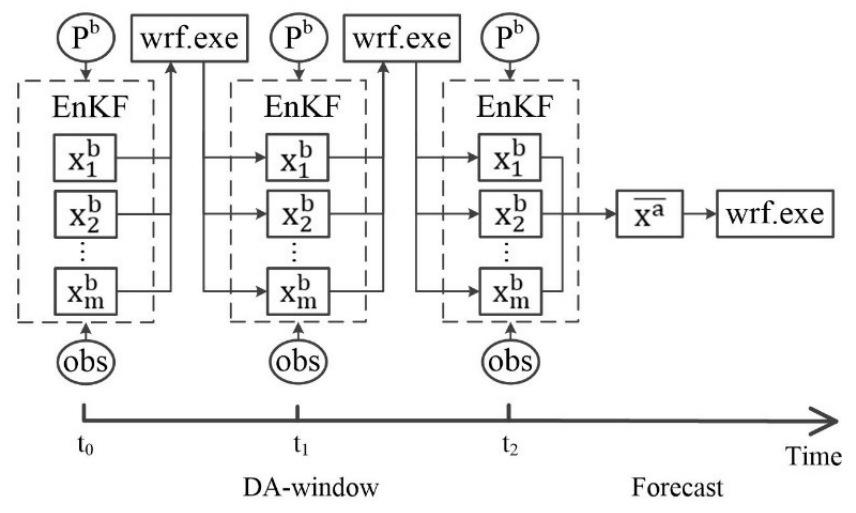

Figure 3. Flowcharts for data assimilation schemes: (a) DA-1, (b) DA-2 and (c) DA-3. See details in the text.

The initial $\left(t=t_{0}\right.$ in Fig. 3$)$ ensembles for DA-2 and DA-3 were created by a random perturbation method (Barker et al., 2004; Wang et al., 2008a, b). In this study, ensemble member was set 40 (i.e., $\mathrm{m}=40$ in Fig. 3). The major difference between 3DVAR and EnKF is the background error covariances, which will cause different assimilation results. However, another factor will also contribute to the assimilation results. It is the ensemble forecast of DA-3 in the DA window, which can lead to the difference of initial conditions even if the update steps are the same. Thus, the purpose of DA-2 scheme is to isolate the contribution of ensemble forecast relative to DA-1. 
Six sea fog forecast experiments were conducted (Table 2), in which Exp-A1-Exp-A3 were designed for the case C-09 and the others were the case C-14. Table 2 summarizes the DA schemes and assimilated observations for each experiment. The forecast staring points were 1200 UTC 09 Apr 2009 and 00UTC 02 Apr 2014 for the cases C-09 and C-14, respectively. Cycling 3DVAR/EnKF assimilations were performed in the DA window before the starting points. For the case $\mathrm{C}-09$, the DA window was $12 \mathrm{~h}$ with a 6-h cycle interval and the forecast length was $24 \mathrm{~h}$. The case C-14 had a 12-h forecast period with 12-h DA window and 3-h cycle interval. The WRF was initialized every $12 \mathrm{~h}$ and run $24 \mathrm{~h}$ for a period of 15 days centered at the staring day of the case forecast. The WRF results were then used to generate a new static background error covariance matrix (i.e., B in Fig. 3) by the NMC method (Parrish and Derber, 1992). The background error uses regression coefficients to correlate wind speed, temperature and pressure, while relative humidity is independent. Note that the flow-dependent background error covariance matrix for EnKF (i.e., $\mathbf{P}^{\mathbf{b}}$ in Fig. 3), in which any two analysis variables are codependent, was statistically calculated based on the ensemble of $\mathbf{x}^{\mathbf{b}}$ and updated in every cycle.

Table 2. Design of experiments.

\begin{tabular}{cccc}
\hline Experiment & Case & Assimilation scheme & Assimilated observation type \\
\hline Exp-A1 & & DA-1 & Radiosonde and surface \\
Exp-A2 & C-09 & DA-2 & measurements, AMSU-A/B, \\
Exp-A3 & & DA-3 & HIRS-3/4, MHS \\
Exp-B1 & & DA-1 & Radiosonde and surface \\
Exp-B2 & C-14 & DA-2 & measurements \\
Exp-B3 & & DA-3 & \\
\hline
\end{tabular}

\section{Results}

\subsection{Methods for sea fog diagnostics and evaluation}

Fog area is the most concerned aspect in the sea fog forecasting. However, it is impossible to 
determine sea fog area by limited observations from ships and buoys over the Yellow Sea. The method that is used by Wang et al. (2014) is employed here to retrieve the sea fog area (hereafter termed "'observed sea fog”') using the MTSAT data.

Sea fog area diagnosed from the model results (hereafter termed "forecasted sea fog") is diagnosed by forecasted liquid water content (LWC). The region with LWC at the lowest model level $\geq 0.016 \mathrm{~g} / \mathrm{kg}$ and the fog-top height $\leq 400 \mathrm{~m}$ is defined as forecasted sea fog (Wang et al., 2014; Yang and Gao, 2016; Zhou and $\mathrm{Du}, 2010)$. The value $0.016 \mathrm{~g} / \mathrm{kg}$ for $\mathrm{LWC}$ is equivalent to 1 $\mathrm{km}$ horizontal visibility calculated using the formula by Stoelinga and Thomas (1999). The fog-top height is the height of the most upper vertical level where the LWC is more than $0.016 \mathrm{~g} / \mathrm{kg}$ in the marine PBL.

Forecasted sea fog is compared hourly with observed sea fog by the statistical scores, including the probability of detection (POD), false alarm ratio (FAR), Bias, and equitable threat score (ETS) (e.g., Doswell and Flueck, 1989; Wang et al., 2014; Zhou and Du, 2010). The domain D2 (see Fig. 2) is taken as the verification area, and the scores are defined by

$$
\begin{gathered}
\mathrm{POD}=\frac{H}{O} \\
\mathrm{FAR}=\frac{F-H}{F} \\
\text { Bias }=\frac{F}{O}=\frac{P O D}{1-F A R} \\
\mathrm{ETS}=\frac{H-R}{F+O-H-R}
\end{gathered}
$$

where $\mathrm{F}, \mathrm{O}$, and $\mathrm{H}$, respectively, refer to the numbers of forecast points, observed points, and correctly forecast points with fog occurrence (i.e., binary value is 1 ); $\mathrm{R}=\mathrm{F}(\mathrm{O} / \mathrm{N})$ is a random hit penalty, and $\mathrm{N}$ is the total number of points in the verification area. 


\subsection{Evaluation of assimilation effect}

\subsubsection{Verification of sea fog area}

Forecasted sea fog of the cases C-09 and C-14 are shown in Fig. 4 and Fig. 5, respectively.

Panels in the top row in both Fig. 4 and Fig. 5 illustrate the observed sea fog, and panels in the other rows give the forecasted sea fog. By through visually comparing the forecasted sea fog with the observed sea fog, it is clearly seen that the forecast experiments (i.e., Exp-A3 and Exp-B3) with DA3 scheme perform best (e.g., cf. Figs. 4t, o, j with Fig. 4e; cf. Figs. 5r, h, m with Figs. 5c).

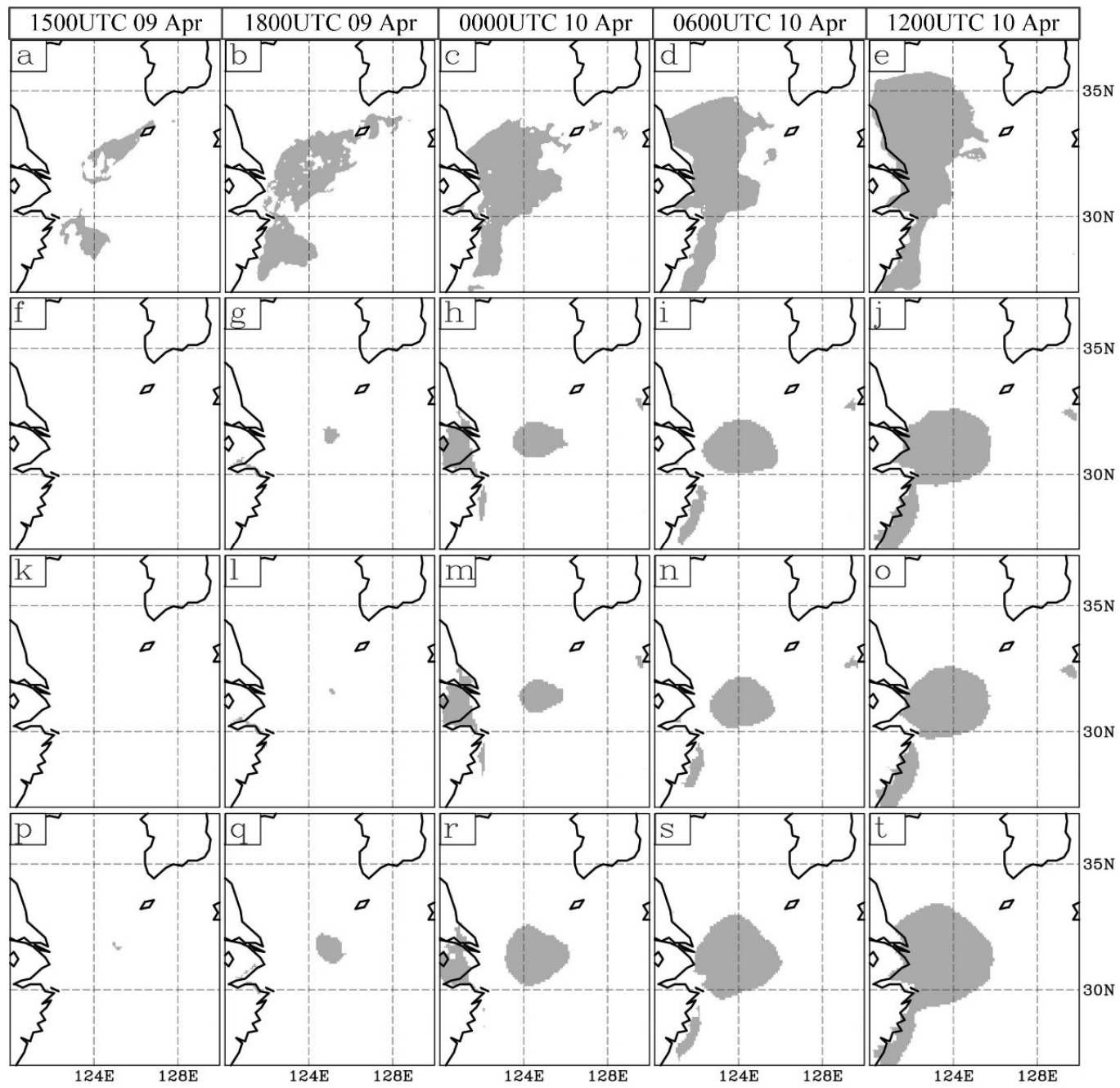

Figure 4. Comparison between the forecasted and observed sea fog areas for the case C- 09 . Panels in the top row are the observed fog patches, and panels in the other rows from up to down are the forecasted fog patches for Exp-A1, Exp-A2 and Exp-A3, respectively. 


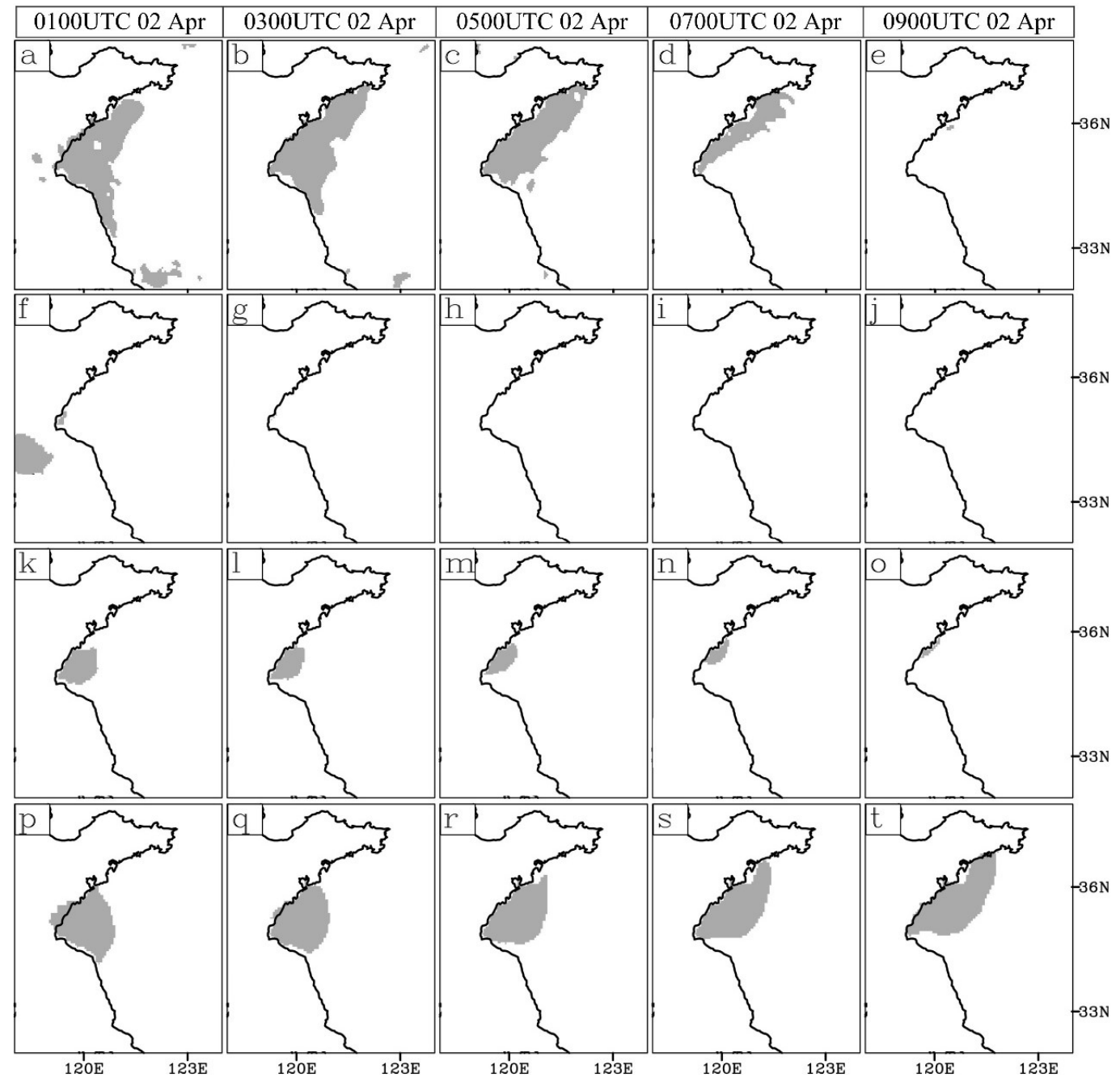

Figure 5. As in Figure4, but for Exp-B1, Exp-B2 and Exp-B3 of the case C-14.

Particularly, Exp-B1 that uses DA-1 scheme completely fails to capture the forecasted sea fog (Figs. 5f-j), whereas Exp-B3 successfully forecasts the sea fog evolution.

Instead of using eyeball comparison, a quantitative evaluation was conducted using of statistical scores defined above. Table 3 outlines the temporally-averaged statistical scores. Compared to Exp-A1, Exp-A3 show obvious improvements, in which POD, FAR, Bias, and ETS are all positive and the ETS gets improved by 55.5\%. Similarly, compared to Exp-B1, all scores of Exp-B3 except 
for FAR have significant improvements especially with an ETS gain of $8320.0 \%$. However, the experiments Exp-A2 and Exp-B2 have the opposite improvement performance: the former negative, the latter positive.

Table 3. Statistical results of the experiments. The improvements (\%) in Exp-A2 and Exp-A3 relative to Exp-A1 are in parentheses and set in boldface, as well as Exp-B2 and Exp-B3 relative to Exp-B1.

\begin{tabular}{lllll}
\hline \multirow{2}{*}{ Experiment } & \multicolumn{4}{c}{ Scores } \\
\cline { 2 - 5 } & POD & FAR & Bias & ETS \\
\hline Exp-A1 & 0.178 & 0.276 & 0.246 & 0.128 \\
Exp-A2 & $0.139(\mathbf{- 2 1 . 9})$ & $0.251(\mathbf{3 . 5})$ & $0.186(\mathbf{- 8 . 0})$ & $0.102(\mathbf{- 2 0 . 3})$ \\
Exp-A3 & $0.281(\mathbf{5 7 . 9})$ & $0.274(\mathbf{0 . 3})$ & $0.387(\mathbf{1 8 . 7})$ & $0.199(\mathbf{5 5 . 5})$ \\
Exp-B1 & 0.006 & 0.173 & 0.007 & 0.005 \\
Exp-B2 & $0.175(\mathbf{2 8 1 6 . 7})$ & $0.027(\mathbf{1 7 . 7})$ & $0.179(\mathbf{1 7 . 3})$ & $0.152(\mathbf{2 9 4 0 . 0})$ \\
Exp-B3 & $0.605(\mathbf{9 9 8 3 . 3})$ & $0.304(\mathbf{- 1 5 . 8})$ & $0.869(\mathbf{8 6 . 8})$ & $0.421(\mathbf{8 3 2 0 . 0})$ \\
\hline
\end{tabular}

As shown in Fig.3 and Table.2, Exp-A2/B2 and Exp-A1/B1 have different the background at the beginning of the DA windows with the same DA scheme, while Exp-A2/B2 and Exp-A3/B3 have the same background but with different DA scheme. According to the above results of sea fog area verification, it suggests that Exp-A3/B3 perform much better than Exp-A1/B1 and Exp-A2/B2 mainly due to the DA-3 scheme.

\subsubsection{Validation by measurements}

Sea fog over the Yellow sea usually forms and develops under a high-pressure weather system with stable marine PBL and suitable moisture condition (Gao et al., 2010; Yang and Gao, 2016). The radiosonde, surface and ship measurements were taken to validate the analysis fields (i.e., ICs). The agreement between the initial analysis and the radiosonde observations (see their sites in Fig. 2) 
were firstly evaluated, focusing on bias and root-mean-square error (RMSE). Figure 6 shows the average vertical profiles of height, temperature, and moisture (represented by the water vapor mixing ratio) over all radiosonde observations.

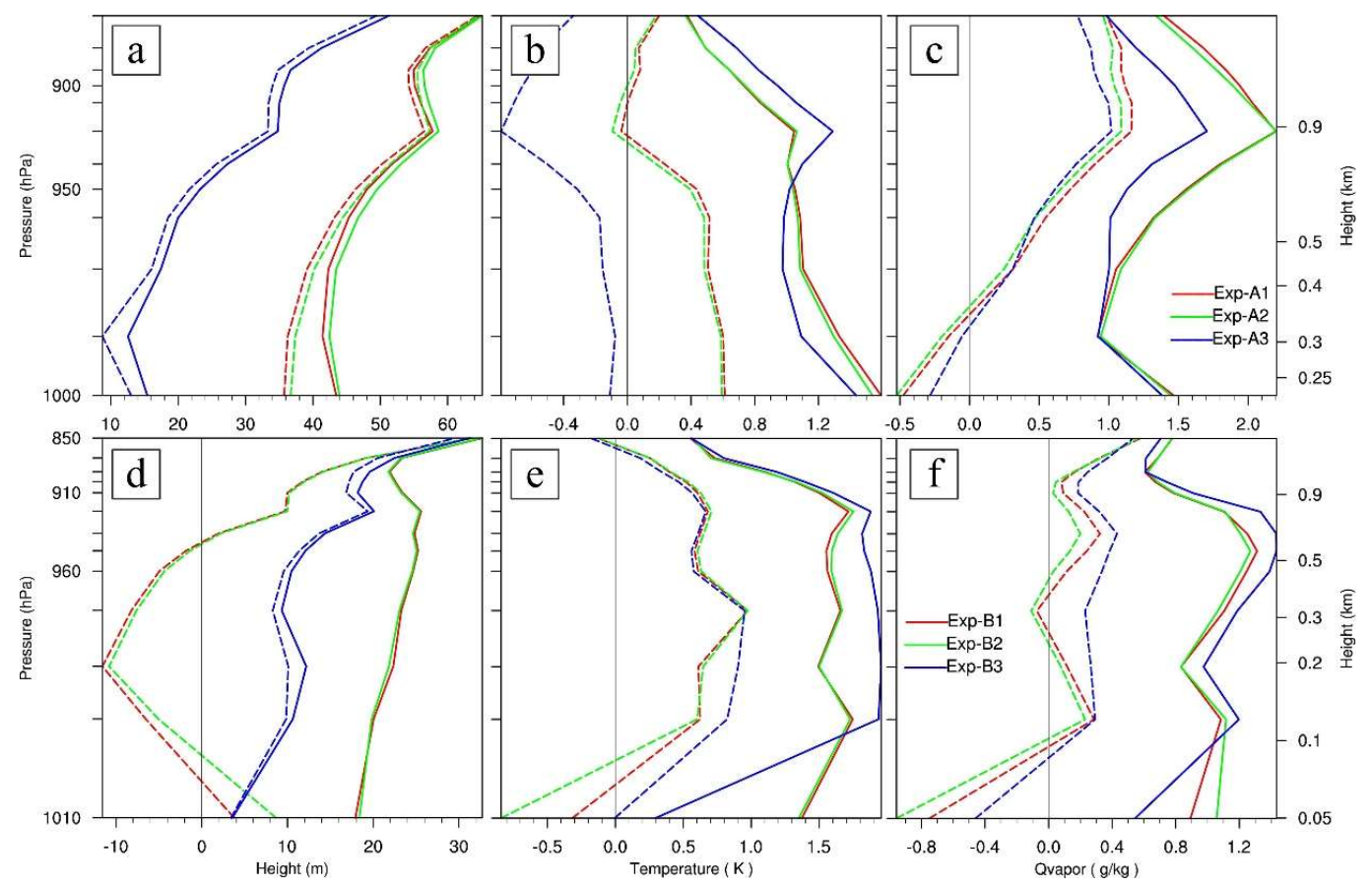

Figure 6. Vertical profiles of the RMSEs (solid lines) and biases (dashed lines) between the initial analysis and the radiosonde observations of geopotential height (left), temperature (middle), and mixing ratio (right). The upper and lower panels are for the cases C-09 and C-14, respectively.

For the geopotential height profiles (Figs. 6a, d), Exp-A3/B3 has much smaller bias and RMSE than Exp-A1/B1, indicating that strength of the high-pressure system in Exp-A3/B3 much more fits the reality. For instance, the average height biases below $950 \mathrm{hPa}$ of Exp-A1/A3 and Exp-B1/B3 are respectively $41.27 / 15.60 \mathrm{~m}$ and $-16.35 / 11.29 \mathrm{~m}$, while the average height RMSEs of Exp-A1/A3 and Exp-B1/B3 are respectively 45.21/17.73 $\mathrm{m}$ and 24.36/12.08 m. Additionally, sea level pressure (SLP) distribution and its RMSE and bias were verified by surface measurements. Figure 7 presents the result for the case $\mathrm{C}-19$, and the result of the case C-14 is quite similar and not shown 
here. It is clearly seen that Exp-A1 and Exp-A2 have almost the same RMSE and bias, however Exp-A3 greatly decreases its RMSE and bias (Figs. 7b, c). Compared with the isobars on KMA surface chart (Fig. 7a), it is also found that the SLP distribution of Exp-A3 is much closer to the observed fact than Exp-A and Exp-B (cf. Figs. 7d-f and Fig. 7a). For example, the $1022.5 \mathrm{hPa}$ contour in Exp-A3 is more consistent with that on the chart than either of Exp-A1 and Exp-A2. At the same time, the improved SLP promotes better sea surface wind (SSW). The forecasted SSW in the region, which is indicated by dashed lines in Fig. 2a , are verified by CCMP wind product. The RMSEs of wind speed (direction) for Exp-A1, Exp-A2 and Exp-A3 are $1.30 \mathrm{~m} / \mathrm{s}\left(25.74^{\circ}\right), 1.17 \mathrm{~m} / \mathrm{s}$ $\left(25.03^{\circ}\right)$ and $1.14 \mathrm{~m} / \mathrm{s}\left(23.70^{\circ}\right)$, respectively.
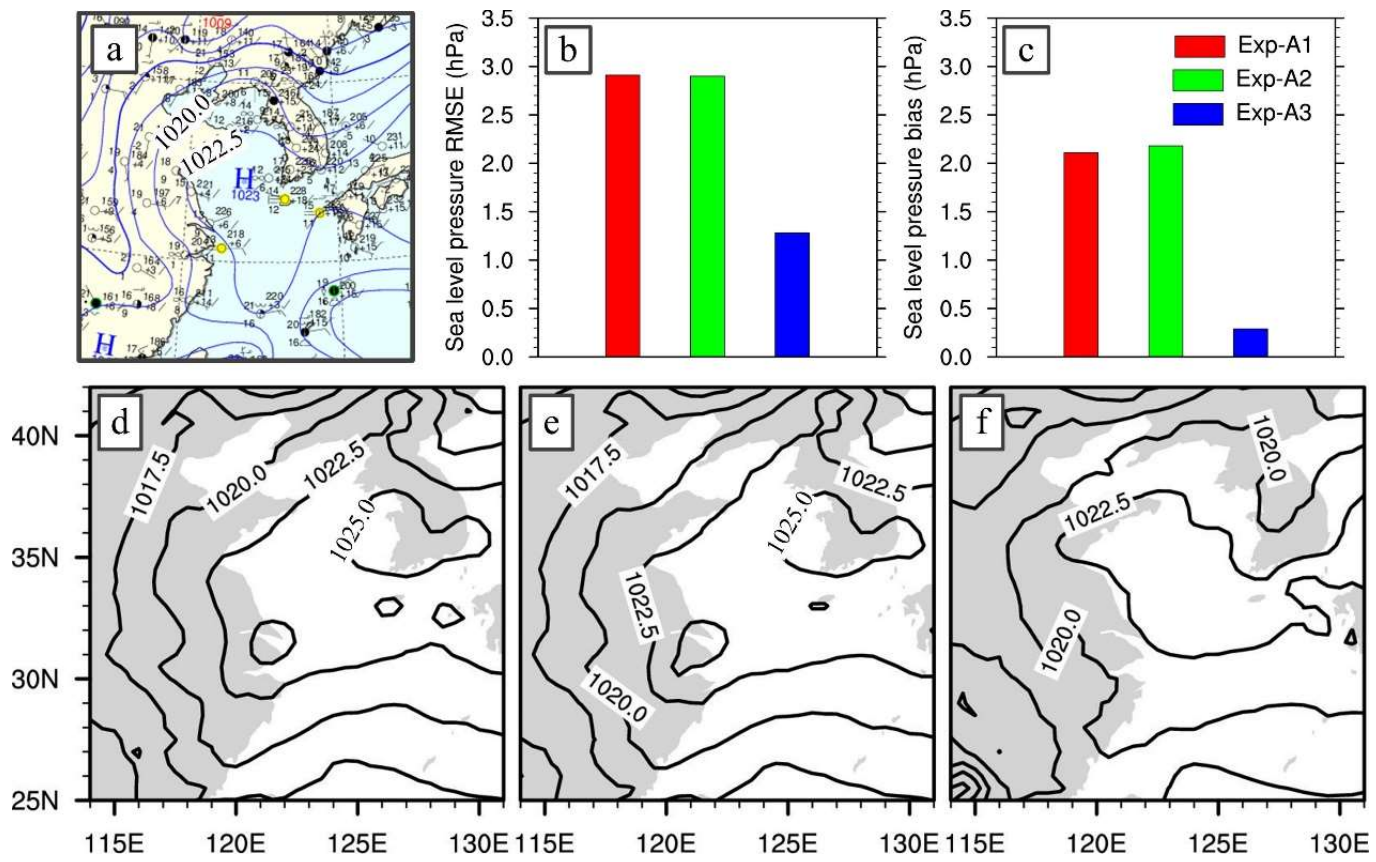

Figure 7. Evaluation result of SLP in the initial analysis for the Case C-09. Top panels respectively show (a) KMA surface synoptic chart, (b) RMSE and (c) bias of SLP by using surface measurements. Bottom panels illustrate SLP of (d) Exp-A1, (e) Exp-A2 and (f) Exp-A3, respectively. 
As well as the profiles of geopotential height, Figure 6 contains the profiles of temperature and mixing ratio. For the case $\mathrm{C}-09$, the profiles of mixing ratio bias and RMSE for Exp-A3 have bestperforming values below $950 \mathrm{hPa}$ (about $600 \mathrm{~m}$; Fig. 6c), as well for temperature (Fig. 6b). The average mixing ratio bias and RMSE below $950 \mathrm{hPa}$ of Exp-A1/A3 are 0.19/0.13 g/ $\mathrm{kg}$ and 1.28/1.09 $\mathrm{g} / \mathrm{kg}$, respectively. Although the profiles of temperature and mixing ratio for Exp-B3 get worse than Exp-B1 and Exp-B2 above $1000 \mathrm{hPa}$ (near 1300 m; Figs. 6e, f), there exist dramatical improvements below $1000 \mathrm{hPa}$. Especially at the $1010 \mathrm{hPa}$ level, the RMSE of temperature drops from $1.4 \mathrm{~K}$ to $0.3 \mathrm{~K}$, and the RSME of mixing ratio decreases from $0.90 \mathrm{~g} / \mathrm{kg}$ to $0.55 \mathrm{~g} / \mathrm{kg}$.

It is worth mentioning that the layers within the marine PBL where temperature and moisture are improved in Exp-A3 and Exp-B3 have obviously different depths: the former about $600 \mathrm{~m}$, while the latter near $130 \mathrm{~m}$. Remind that the fog patch of the case C-09 is deeper than that of the case C-14, which has been suggested previously in the end of Section 3.2. It seems that the two things might be related.

Furthermore, the forecasted moisture over sea is validated using ship measurements (locations marked by black dots in Fig. 2) during the forecast time. The result is shown in Fig. 8. For the case C-09 (Fig. 8a), the mixing ratio forecasted by Exp-A3 performs better than Exp-A1 and Exp-A2 at S1-4, and performs worse than Exp-A1 and Exp-A2 at S7. Exp-A1 and Exp-A3 have almost the same mixing ratio biases at S5 and S8. The RMSEs of Exp-A1-A3 are 0.59, 0.56 and $0.51 \mathrm{~g} / \mathrm{kg}$, respectively. For the case C-14 (Fig. 8b), biases are larger, and Exp-B3 overwhelms both Exp-B1 and Exp-B2 for most observation locations. The RMSEs of Exp-B1-B3 are 2.03, 2.04 and 1.74 $\mathrm{g} / \mathrm{kg}$, respectively. The validation result indicates that DA-3 produces a better moisture structure over sea. 


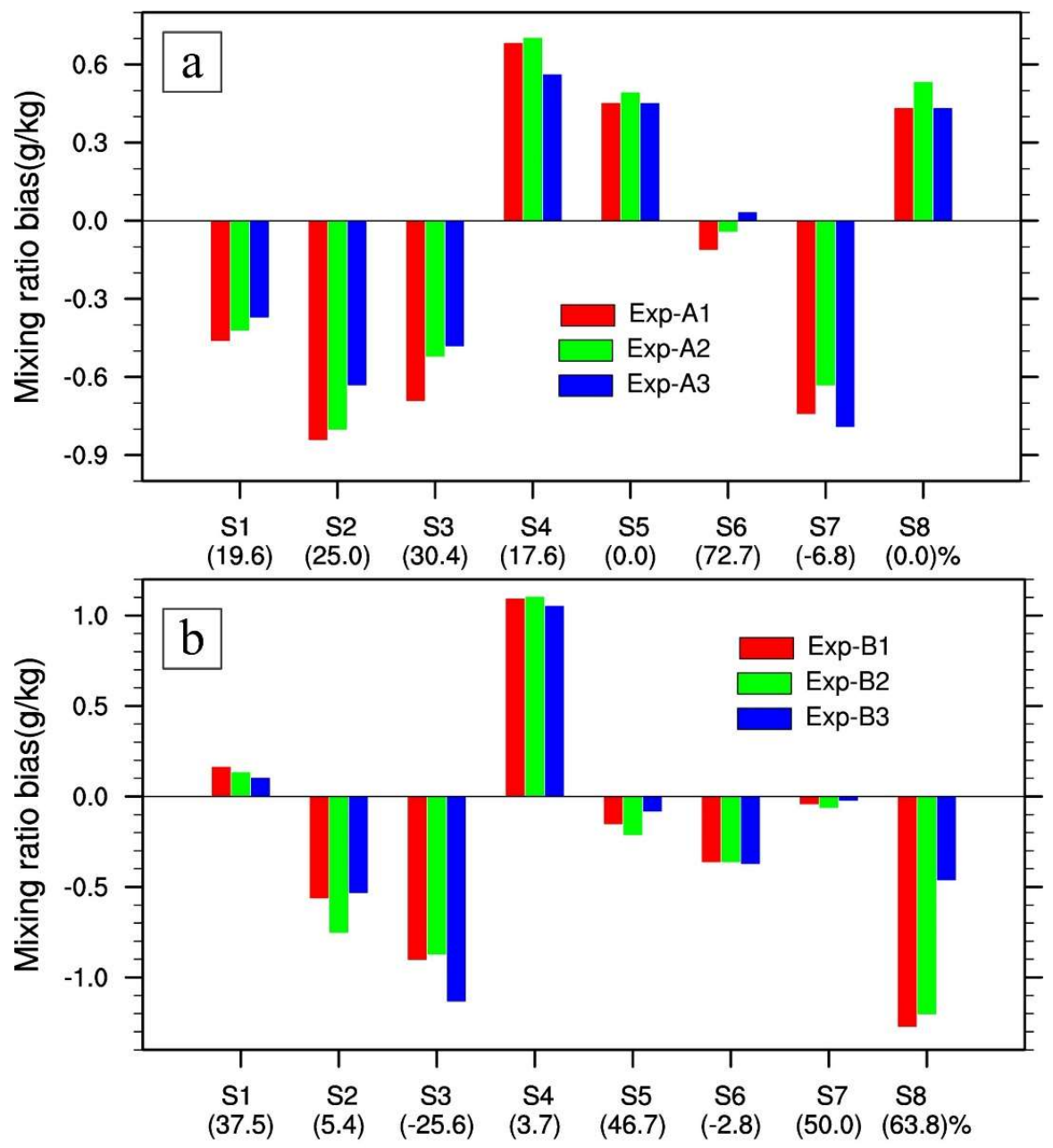

Ship No.

Figure 8. Biases between the forecasted and observed mixing ratio for the cases (a) C-09 and (b) C14. Numbers in parentheses are the mixing ratio of ship measurements. The improvements (\%) of ExpA3 relative to Exp-A1 and are in parentheses below horizontal coordinates, as well as Exp-B3 relative to Exp-B1.

\subsection{Investigation of assimilation effects}

\subsubsection{Feature of initial condition differences}

Results of the evaluation on assimilation effect demonstrate that the DA-3 scheme outperforms the other DA schemes evidently. The two sea fog cases, one spread widely over the Yellow Sea and the other spread narrowly along the Shandong Peninsula coast, can both obtain obvious forecast 
improvement by using EnKF other than 3DVAR. Next, we will discuss the issue on how 3DVAR and EnKF work for the improvement and how they differ in the assimilation process for the two sea fog cases.

Differences between the initial conditions of different experiments are investigated. Figure 9 shows the initial condition difference near sea surface of Exp-A2 minus Exp-A1, and Exp-A3 minus Exp-A1 for the case C-09. It is similar in Fig. 10 but for the case C-14. It is clear there are rather small differences when the DA-2 scheme is used instead of the DA-1 scheme (see the upper panels in both Fig. 9 and Fig. 10). However, when the DA scheme is changed from DA-1 to DA-3, the differences are significant (see the bottom panels in both Fig. 9 and Fig. 10).
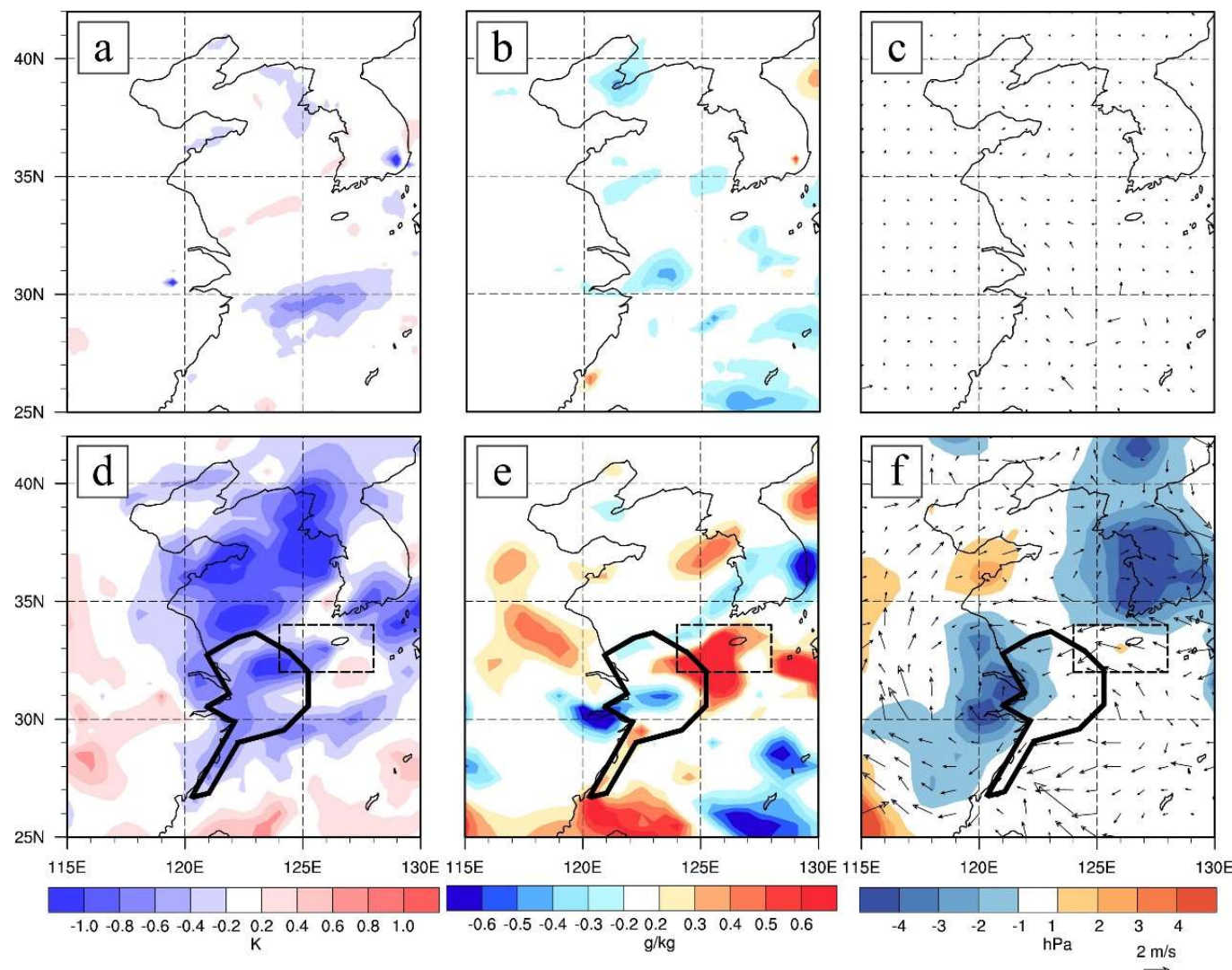

Figure 9. Initial differences of temperature (left) and mixing ratio (middle) at $1000 \mathrm{hPa}$, SLP and 10$\mathrm{m}$ wind (right) between Exp-A2 and Exp-A1 (upper), Exp-A3 and Exp-A1 (lower), respectively. The dashed frame indicates the significant zone, and the closed thick solid line denotes the forecasted sea 
fog at 1200 UTC 10 Apr 2009.

For the areas that overlap or neighbor where sea fogs occur (sea fog areas are denoted by the closed thick solid lines in Fig. 9 and Fig. 10), the differences become obviously larger. The values of temperature, mixing ratio, wind speed and SLP that these differences can reach are about $1.0 \mathrm{~K}$, $0.6 \mathrm{~g} / \mathrm{kg}, 3.0 \mathrm{~m} / \mathrm{s}$ and $4 \mathrm{hPa}$, respectively. For instance, the area marked with a dashed frame has large differences of mixing ratio and wind, which locates northeast to the fog area (Figs. 9e, f); however, the area covering over forecasted sea fog in the case $\mathrm{C}-14$, there are distinguished large differences of temperature (Fig. 10d), mixing ratio (Fig. 10e) and SLP (Fig. 10f). For convenience of reference, the above two areas stamped by dashed frames are called significant zones.
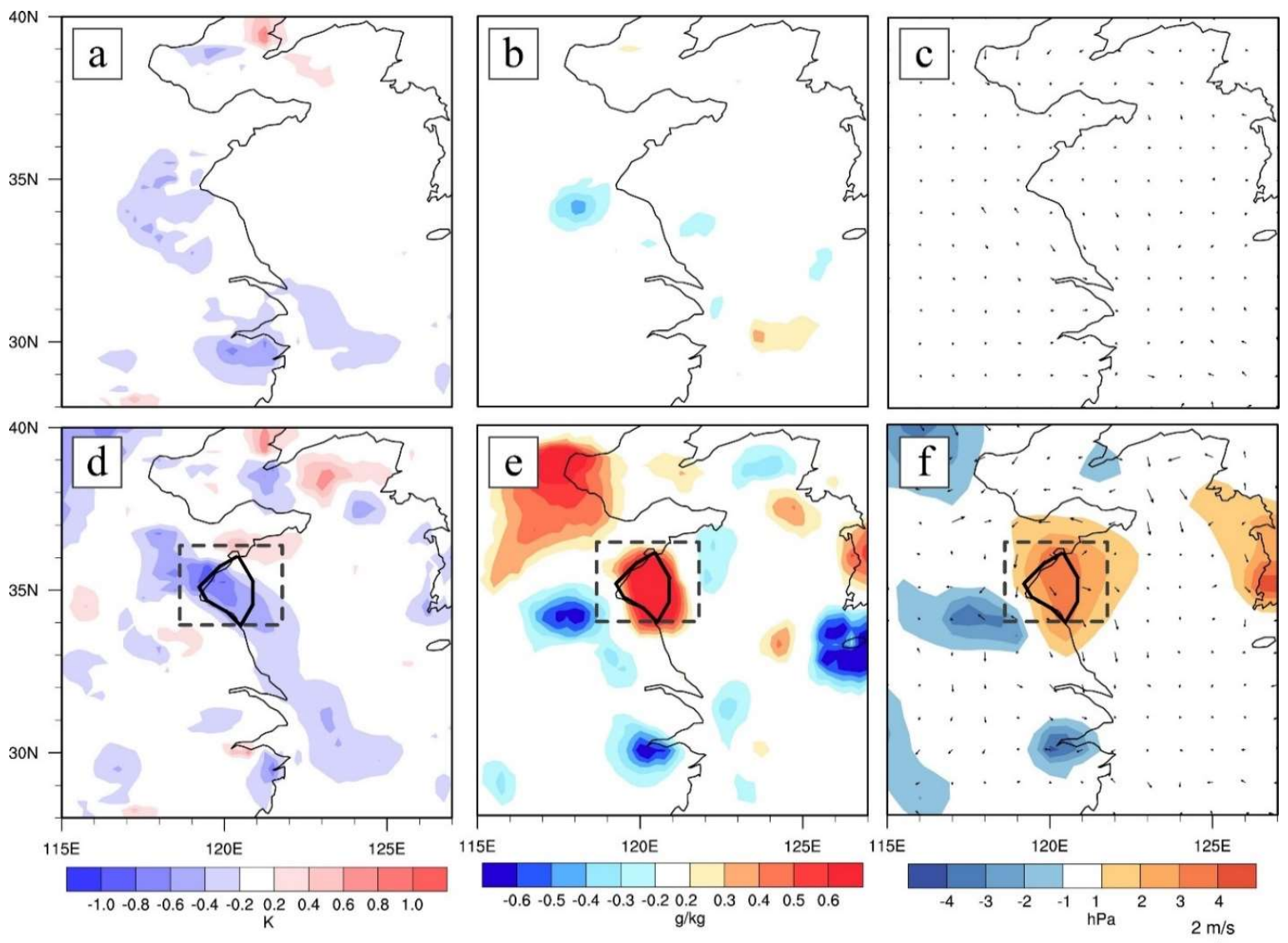

Figure 10. As in Figure 9, but for difference between Exp-B2 and Exp-B1 (upper), Exp-B3 and Exp- 
B1 (lower), and the forecasted sea fog at 0100 UTC 02 Apr 2014.

After having an insight into the evolution of forecasted sea fog in the sea fog cases (Fig. 4 and Fig. 5), it is found that the forecast improvement is embodied in the development stage for the case C-09 (e.g., cf. Figs. 4i, n, s and Fig. 4d), but for the case C-14 the forecast improvement is already spotted in the initial stage (cf. Figs. 5f, k, p and Fig. 5a). It implies that the mechanisms of data assimilation for the two cases might be different.

Combing the above information, two questions for further analysis are proposed here:

- Are the forecast improvements closely related to the significant zones?

- If the answer is yes to the above question, then how are the significant zones formed in the assimilation process?

\subsubsection{Reason of the forecast improvements}

For the case C-14, Exp-B1 completely fails, resulting in no sea fog in the whole forecast period (Fig. 5). However, Exp-B3 successfully capture the sea fog process from the beginning. The positive mixing ratio difference at $1000 \mathrm{hPa}$ in the significant zones (cf. Fig. 10b and Fig. 10e), which shows it is about $0.6 \mathrm{~g} / \mathrm{kg}$ wetter in Exp-B3 that Exp-B1, indicates that the failure of Exp-B1 may be due to lack of enough moisture. On the contrary, the success of Exp-B3 results from enough moisture (Fig. 10e) additionally with a strengthening high-pressure (Fig. 10f and Fig. 1c), which means the atmospheric stratification is more stable and suitable for sea fog occurrence.

Figure 11 furtherly gives the observation innovation (i. e. , $\mathbf{y}-\mathbf{H} \mathbf{x}^{\mathrm{b}}$ ) and analysis increment (i. e., $\left.\mathbf{x}^{\mathrm{a}}-\mathbf{x}^{\mathrm{b}}\right)$ at the lowest model level for Exp-B1 and at the last DA cycle $\left(t=t_{2}\right.$ in Fig. 3$)$. Prior to the assimilation of this cycle, the observation innovations and analysis increments of temperature and 
mixing ratio differ very little between Exp-B1 and Exp-B3 (cf. Fig 11a and Fig. 11d; cf. Fig 11b and Fig. 11e). It means that Exp-B1 and Exp-B3 have almost the same backgrounds (i.e., $\mathbf{x}^{\mathbf{b}}$ ) of temperature and mixing ratio. However, after assimilating new observations, Exp-B1 and Exp-B3 obtain distinctly different analysis increments (Figs. 11c, f). In the significant zones, both Exp-B1 and Exp-B3 get negative temperature increment, but the amplitude of the former is much smaller than that of the latter; Exp-B1 has nearly no gain of mixing ratio, whereas the gain of Exp-B3 increases up to $0.2 \mathrm{~g} / \mathrm{kg}$ at least almost over the whole significant zone.
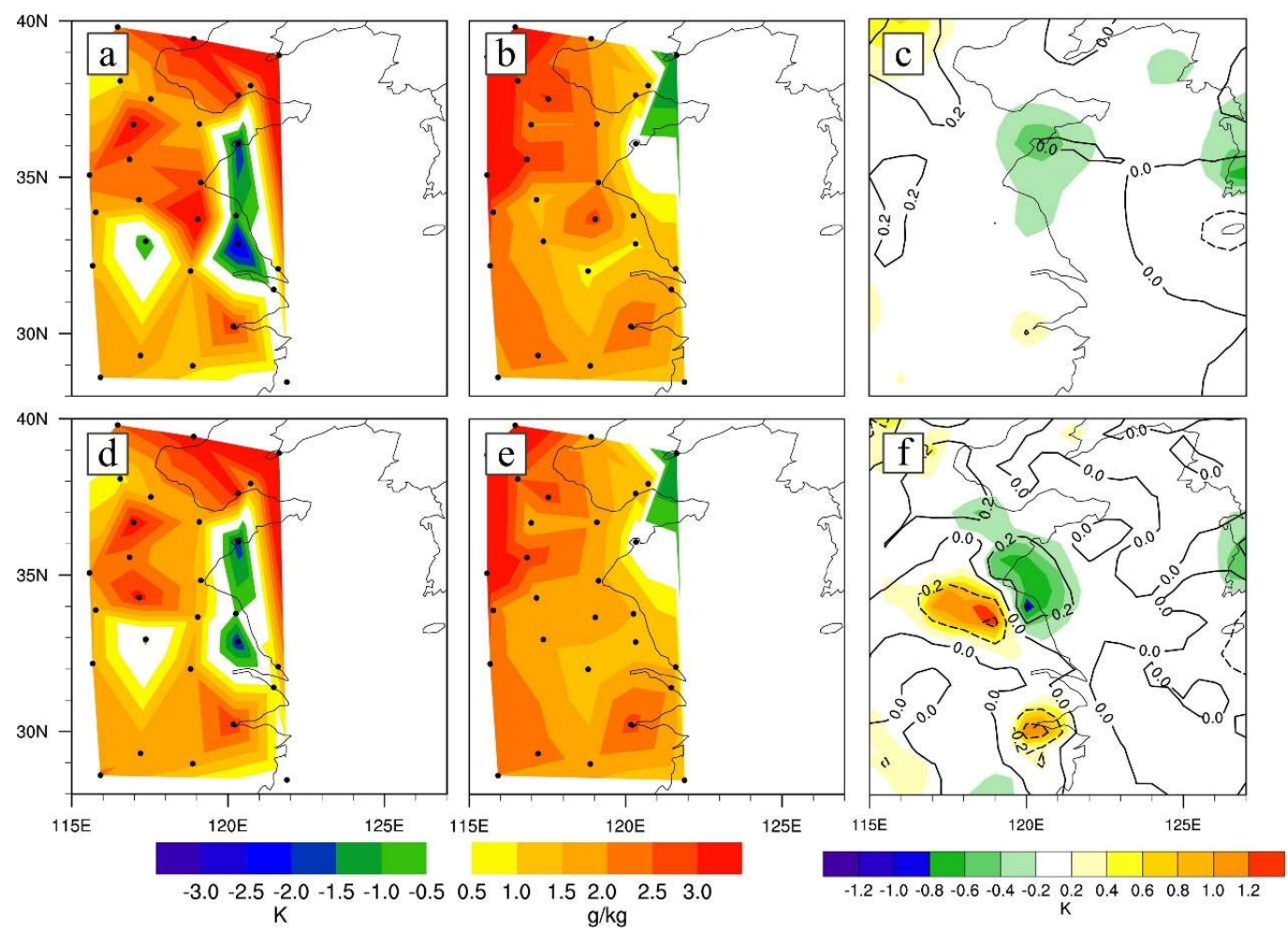

Figure 11. Comparison of observation innovation $\left(\mathbf{y}-\mathbf{H} \mathbf{x}^{\mathrm{b}}\right)$ and analysis increment $\left(\mathbf{x}^{\mathrm{a}}-\mathbf{x}^{\mathrm{b}}\right)$ at the lowest model level between Exp-B1 (upper) and Exp-B3 (bottom) for the last DA cycle. Observation innovations of temperature and mixing ratio before and after assimilation are illustrated in the left and middle panels, respectively; and analysis increments of temperature (colors) and mixing ratio (contours, unit: $\mathrm{g} / \mathrm{kg}$ ) are shown in the right panels. 
To be brief, the marine PBL below $1000 \mathrm{hPa}$ of Exp-B3 is much wetter than that of Exp-B1 in the initial condition over significant zone, contributing to the successful forecast of Exp-B3. Unlike the case C-14, the significant zone of the case C-09 does not locate over the sea fog area (Fig. 9). The case C-09 gains its forecast improvement in the developing stage instead of the beginning (Fig. 4), and it seems that the expansion of the fog area (cf. Fig. 4t and Fig. 4j) depends to great extent on the strengthened flow (Fig. 9f).

To understand the relationship between the significant zone and the forecast improvement in Exp-A3, evolution of the averages of temperature, mixing ratio, and $\mathrm{u}$ - and v-components of wind over the zone during the DA window and forecast period are demonstrated by the time series in Fig.

12. At the forecast beginning $(\mathrm{t}=0)$, compared to Exp-A1, Exp-A3 has lower temperature (Fig.12a), higher humidity (Fig.12a), and stronger southeasterly wind (smaller u- and v-components; Fig.12c, d), which agrees well with these differences in Fig. 9. This trend continues during the whole forecast period, resulting in moisture advection from the significant zone to the fog area (Figs. 9e, f) and promoting the forecast improvement.

\subsubsection{Impact of the background error}

As seen in the above reason analysis, the sea fog forecast improvements are clearly related to the significant zones in the two fog cases. Next, we try to explain the formation of the significant zones, and compare the impact of background error on the formation by 3DVAR and EnKF.

In the assimilation process, analysis increment represents the gain of assimilating observations jointly controlled by the background error and observation error. Since observation error is usually confirmed in advance, background error becomes the key factor to determine the analysis increment. If we focus on inspecting the analysis increments in Fig. 11 and Fig. 12, it is found that there are two 
noteworthy facts. One fact is that increments of the 3DVAR are generally larger than the EnKF in the case C-09 (see the bars in Fig.12) except for humidity. The other one is that in the case C-14 there is a seesawing relationship of the increments between temperature and humidity in the EnKF but not in the 3DVAR. Namely that negative temperature increment corresponds to positive humidity increment, and vice versa (Fig. 11f). According to the theoretical introduction in Section 2, these two facts involve the variance and covariance of the background error.
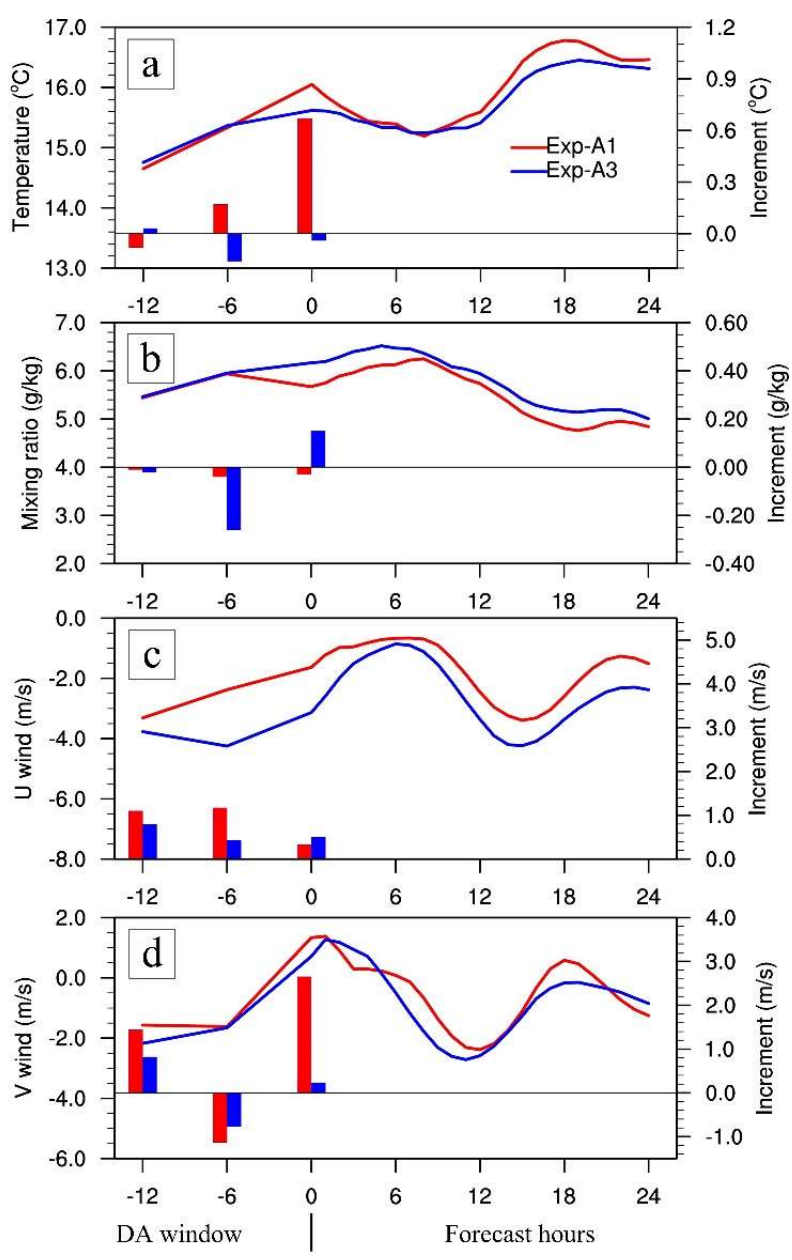

Figure 12. Time series of the average (a) temperature, (b) mixing ratio, (c) $u$ and (d) $v$ wind components over the area marked by the dashed frame in Figure8 for Exp-A1 (red) and Exp-A3 (blue). The bars show the analysis increments within data assimilation window.

The formula (3) is taken to calculate the background-error variance for 3DVAR. Removing $\mathbf{H}^{\mathrm{T}}$ 
from the formula (6) yields the formula to estimate the background-error variance for EnKF:

$$
\mathbf{P}^{\mathrm{b}} \approx \frac{1}{\mathrm{~m}-1} \sum_{\mathrm{i}=1}^{\mathrm{m}}\left(\mathbf{x}_{\mathrm{i}}^{\mathrm{b}}-\overline{\mathbf{x}^{\mathrm{b}}}\right)\left(\mathbf{x}_{\mathrm{i}}^{\mathrm{b}}-\overline{\mathbf{x}^{\mathrm{b}}}\right)^{\mathrm{T}}
$$

Forecast differences of a half-month-long term are used in the formula (3), but instead the formula (12) employs member differences at a certain time. Figure 13 shows the background-error variances of temperature, relative humidity and wind speed at $1000 \mathrm{hPa}$ for the case $\mathrm{C}-09$. Figure 14 is as the same as Figure 13 but for the case $\mathrm{C}-14$, and the variances are calculated in the last cycle. Note that the variances for 3DVAR do not vary within the whole assimilation window. Overall, the variances of 3DVAR are larger than EnKF over sea (cf. the upper row and the bottom row in Fig. 13 and Fig. 14). Since observation error can be considered fixed, larger variances make assimilation result approach closer to observation than to background. This may explain the first fact mentioned above: why variables' increments of 3DVAR are generally larger than those of EnKF in the assimilation window (see the bars in Fig. 12). 

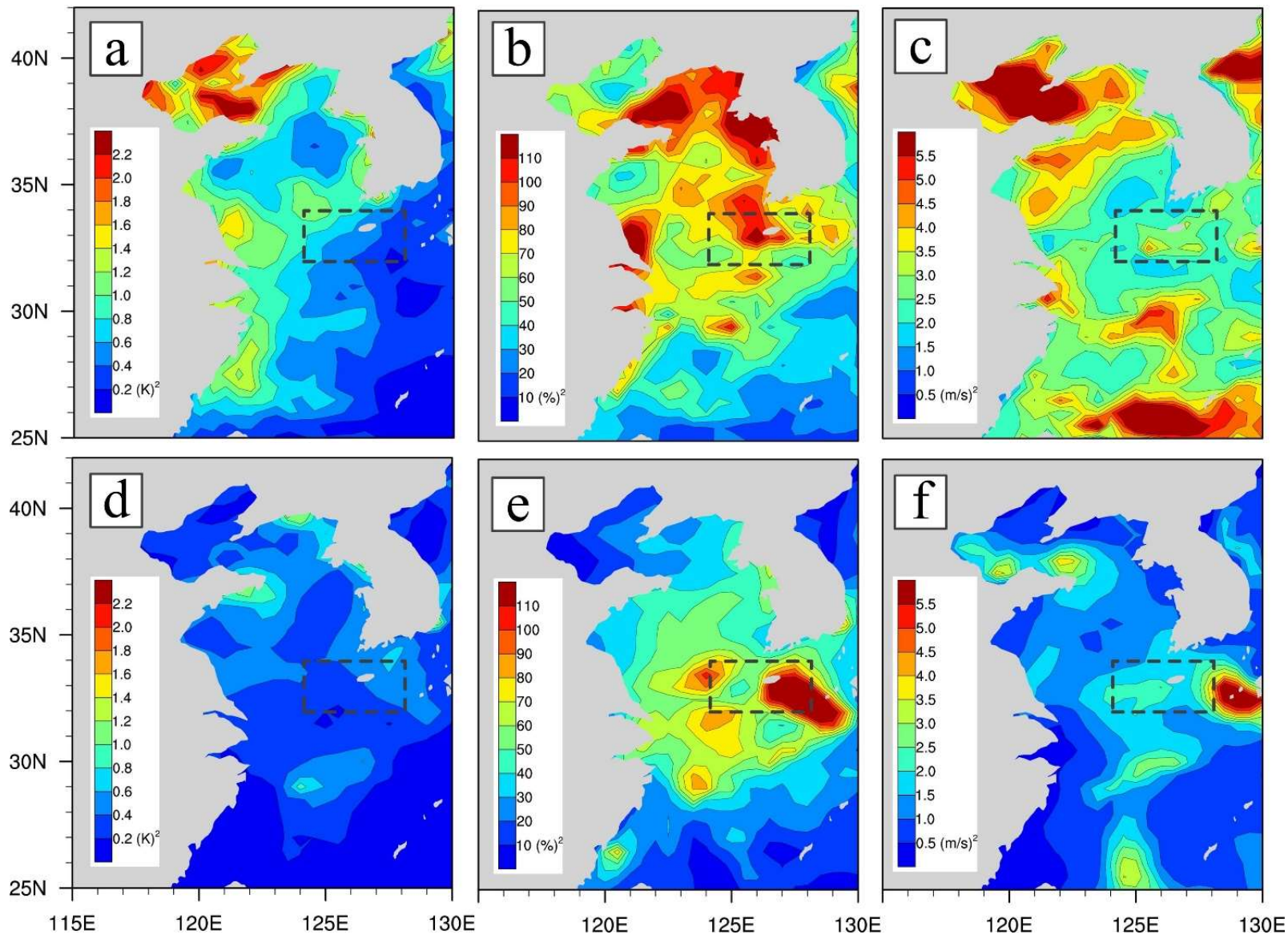

Figure 13. Comparison between the variance distributions at $1000 \mathrm{hPa}$ for temperature (left), relative humidity (middle) and wind speed (right) for 3DVAR (upper; Exp-A1) and EnKF (lower; Exp-A3) of the case C-09. The dashed frame indicates the significant zone. 

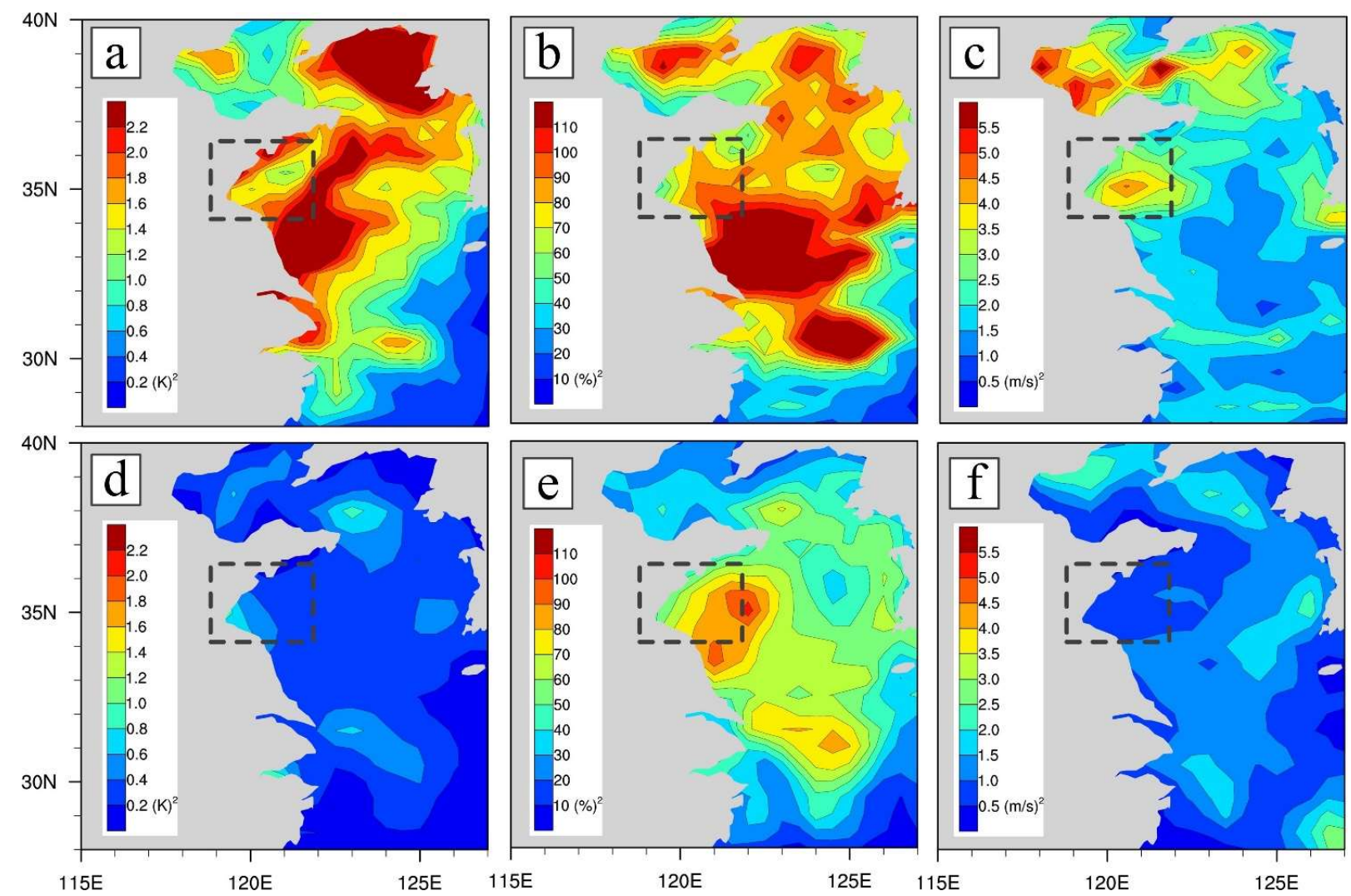

Figure 14. As in Figure 13, but for Exp-B1 and Exp-B3 of the case C-14.

To clearly reveal the impacts of the background-error variances and covariances from 3VAR and

EnKF, six assimilation experiments with single synthetic observation were conducted in the last

cycle. Their description is given in Table 4. Two points (points A and C) are deliberately arranged locating in the significant zones for the two cases, respectively. In addition, another point (point B) is placed in the Taiwan Strait to further demonstrate the flow-dependent feature of EnKF. The values of the observation are given based on the real relation between the observation and the background. 
Table 4. Description of single observation tests.

\begin{tabular}{|c|c|c|c|c|}
\hline Experiment & Case & Location & $\begin{array}{l}\text { Assimilation } \\
\text { method }\end{array}$ & Observation \\
\hline Exp-AS1 & \multirow{4}{*}{ C-09 } & \multirow{2}{*}{$\mathrm{A}\left(125.00^{\circ} \mathrm{E}, 33.00^{\circ} \mathrm{N}\right)$} & 3DVAR & \multirow{4}{*}{$\begin{array}{l}2 \mathrm{~m} / \mathrm{s} \text { u-component wind } \\
\text { above the background }\end{array}$} \\
\hline Exp-AS2 & & & EnKF & \\
\hline Exp-AS3 & & \multirow{2}{*}{$\mathrm{B}\left(120.00^{\circ} \mathrm{E}, 25.00^{\circ} \mathrm{N}\right)$} & 3DVAR & \\
\hline Exp-AS4 & & & EnKF & \\
\hline Exp-BS1 & $C_{-14}$ & $\mathrm{C}\left(12033^{\circ} \mathrm{F} \quad 3607^{\circ} \mathrm{N}\right)$ & 3DVAR & $2 \mathrm{~K}$ temperature below \\
\hline Exp-BS2 & $C-14$ & $\mathrm{C}\left(120.33^{\circ} \mathrm{E}, 36.0 / \mathrm{N}\right)$ & EnKF & the background \\
\hline
\end{tabular}

Figure 15 shows that the different responses of 3DVAR and EnKF to assimilating of a single synthetic u-component wind observation of a value of $2 \mathrm{~m} / \mathrm{s}$ above the background flow (arrows in Fig. 15). The increment of EnKF is smaller than that of 3DVAR due to the difference of background-error variances. The former is about $0.8 \mathrm{~m} / \mathrm{s}$ while the latter is about $1.2 \mathrm{~m} / \mathrm{s}$ at the point A (the top right point in Fig. 15). The corresponding background-error variances of 3DVAR are larger than that of EnKF, which can be seen in comparing the background-error variances in the significant zones of Fig. 13e and Fig. 13f. Because the background flow is easterly, smaller ucomponent wind increment of EnKF makes stronger easterly wind than that of 3DVAR, which may interpret the wind increments in the significant zone in Fig. 9f. The almost same result is shown at the point B. Beyond that, the flow-dependent characteristics of EnKF is clearly found in Fig.15. Even though the observation measures the values of $\mathrm{u}$-component at one point, the data assimilation has spread out this information. However, the spreads of 3DVAR and EnKF differ so much. For 3DVAR, the spread patterns at points A and B are almost the same though the background flow is markedly different (Fig. 15a). But for EnKF, the spread patterns are closely corelated with the flow resulting by its flow-dependent background-error covariances (Fig. 15b). 


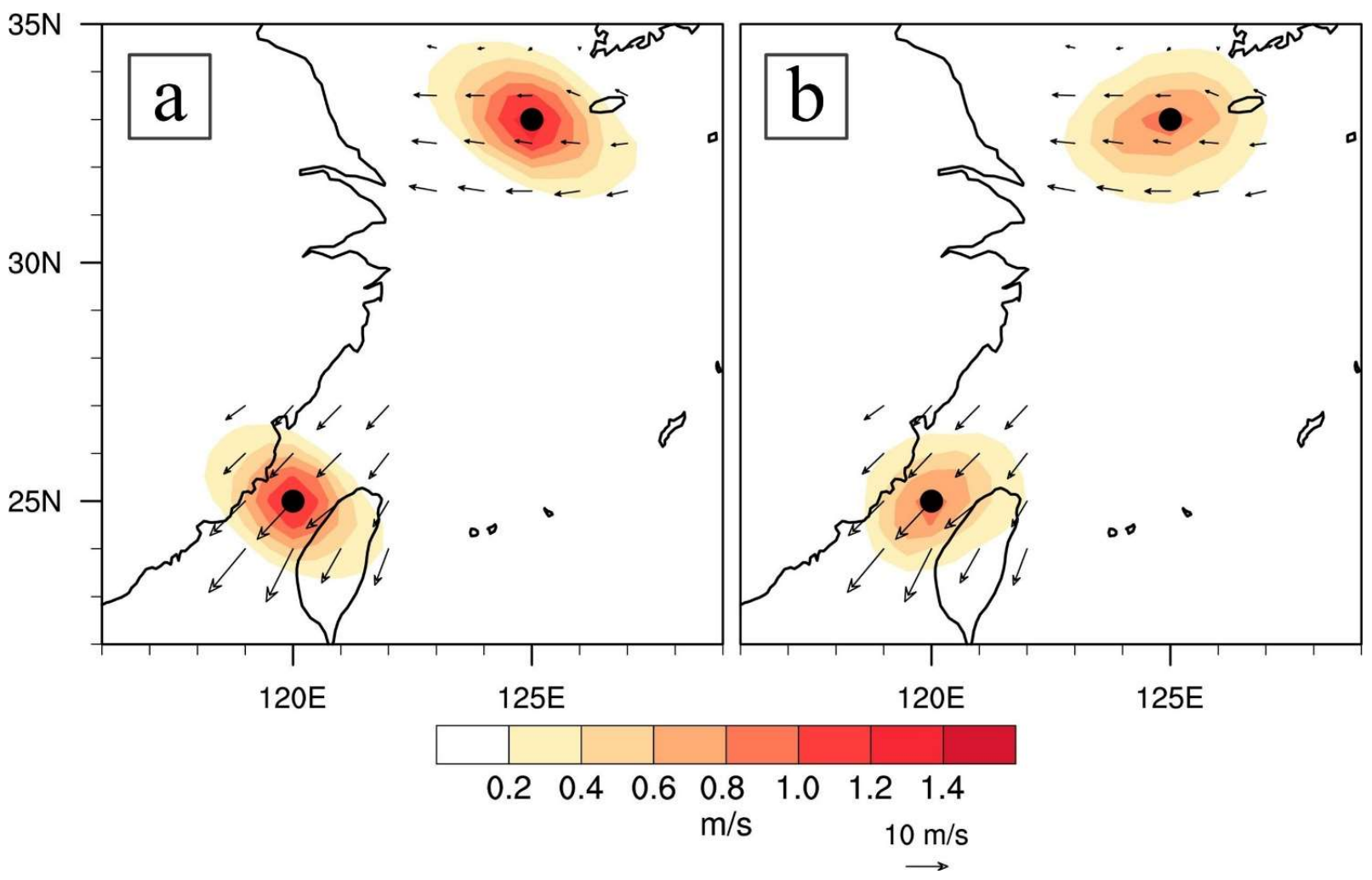

Figure 15. Comparison between (a) 3DVAR and (b) EnKF for mixing ratio (blue contours, unit: $\mathrm{g} / \mathrm{kg}$ ) and $\mathrm{u}$ wind component (colors) increments at $1000 \mathrm{hPa}$ in single synthetic observation tests from ExpAS1 to Exp-AS4. Vectors show background flow.

Moisture increments in the assimilation process especially benefit from the multivariate correlations of EnKF, which has been well certified by the result of Exp-B3. Here, this benefit is simply illustrated in Fig. 16. Given a single synthetic temperature with a value of $2 \mathrm{~K}$ below the background at the point C, 3DVAR only responses to the temperature itself (Fig. 16a), however the response of EnKF includes not only the temperature but also the mixing ratio (Fig. 16b). The amplitude pattern of the temperature increments is almost the same as that of the background-error variances of temperature (cf. the color shadings in Fig. 16b and Fig. 16c), indicating that the temperature assimilation strongly depends on the background-error variances of temperature. However, the assimilation of mixing ratio is chiefly controlled by the background-error covariances 
between relative humidity and temperature (cf. the color shading in Fig. 16d and the contours in Fig. 16b).
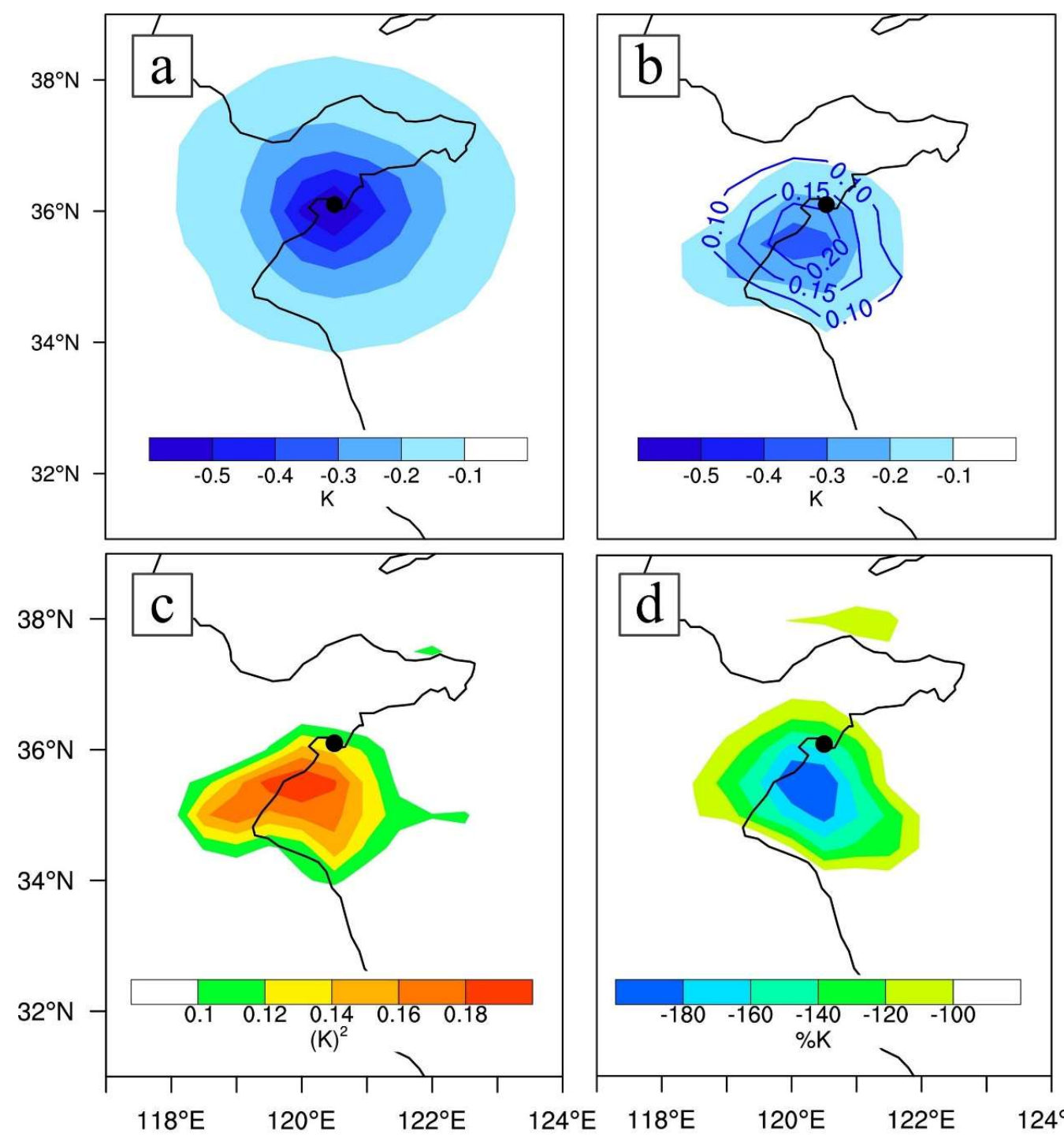

Figure 16. Results of (a) Exp-BS1 and (b)-(d) Exp-BS2. Colors in (a) and (b) show temperature increments $(\mathrm{K})$ and contours in (b) represent mixing ratio increments $(\mathrm{g} / \mathrm{kg})$; Covariances between temperature at the dot and (c) temperature or (d) RH at each model grid are illustrated.

\section{Summary}

Numerical forecasting of sea fog is undoubtedly challenging. It can be tricky due to many imperfect aspects closely related to sea fog simulation, such as microphysics scheme for vapor 
condensation with aerosol effect, turbulence scheme for air-sea interaction in the bottom of marine PBL, subsidence inversion caused by a high, warm-moisture advection controlled by a cyclone/anticyclone couplet, and the initial conditions. Particularly, the last reason is vital for sea fog modeling. Some works have been done previously for it based on 3DVAR method.

In view of the theoretical advantages of EnKF and its effective applications on some weather phenomena except sea fog, two sea fog cases over the Yellow sea were studied in details. There are distinguished differences between the two sea fogs, one spread widely and the other spread narrowly along the coastal area. A series of data assimilation and forecast experiments were conducted aiming at the comparison between 3DVAR and EnKF for the data assimilation effects on the Yellow Sea fog forecast. The results of the experiments, including forecasted sea fog area, vertical profiles of temperature and moisture in the initial conditions, were evaluated by retrieved sea fog patch and measurements. The main conclusions of this research work are summarized below:

1) The assimilation effect of EnKF obviously excel that of 3DVAR, performing at not only forecasted sea fog but also the distribution of temperature, moisture and wind in the initial conditions. For the widespread-fog case, the assimilation by EnKF significantly improves the forecasted sea fog area, raising POD and ETS by up to about $57.9 \%$ and $55.5 \%$, respectively. Especially for the case that spread along the coast, the assimilation by EnKF successfully produces the sea fog that is completely mis-forecasted by 3DVAR.

2) The analysis increments strongly depend on the background error. The flow-dependent background error of EnKF out-competes that of 3DVAR, as evidenced by more realistic depiction of sea surface wind for the widespread-fog case and better existence of moisture for the other case in the initial conditions. 
3) Compared with 3DVAR, the multivariate correlations (e.g., correlation between temperature and humidity) in the background error of EnKF plays a key role on adjusting/generating moisture through assimilating of temperature. It helps greatly to improve the moisture conditions for sea fog forecast.

Further studies are still needed, though encouraging results have been achieved in this study. For instance, why in the initial condition of the widespread-fog case, no sea fog is formed responding to the assimilation by EnKF as that of the other case? It is not enough to clarify in detail the advantages of EnKF on sea fog assimilation only using two sea fog cases, hence more cases are required in the next study. In addition, the forecast experiments with EnKF assimilation are deterministic, in which the mean of the ensemble of assimilation analyses is taken as the initial condition. As a matter of fact, it is easy and convenient to carry out ensemble forecast of sea fog initialized by the members of EnKF, and therefore sea fog ensemble forecast based on EnKF will be desirable. 


\section{Author Contributions:}

X. G. and S. G. designed the experiments and wrote this manuscript. Y. Y. participated in writing and correcting of this manuscript.

\section{Acknowledgments}

This research was financially supported by the National Key Research and Development Program of China (2017YFC1404200), the National Natural Science Foundation of China (41276009), and the National Special Fund for Public Sector Research of China (GYHY201505007). We would appreciate UCAR/NCAR/CISL/TDD for providing a powerful graphic tool NCL (http://dx.doi.org/10.5065/D6WD3XH5).

\section{Conflicts of Interest:}

The authors declare no conflict of interest. 


\section{References}

Ballard, S. P.; Golding B. W.; Smith R. N. B. Mesoscale model experimental forecasts of the haar of northeast Scotland. Mon. Wea. Rev. 1991, 119, 2107-2123.

Barker, D. M.; Huang, W.; Guo, Y. R.; Bourgeois, A. J.; Xiao ,Q. N. A three-dimensional variational data assimilation system for MM5: Implementation and initial results. Mon. Wea. Rev. 2004, 132, 897-914.

Bouttier, F. A dynamical estimation of forecast error covariances in an assimilation system. Mon. Wea. Rev. 1994, 122, 2376-2390.

Chen, F.; Dudhia J. Coupling an advanced land surface-hydrology model with the Penn State-NCAR MM5 modeling system. Part I: Model description and implementation. Mon. Wea. Rev. 2001, 129, 569-585.

Courtier, P.; Talagrand, O. Variational Assimilation of Meteorological Observations With the Adjoint Vorticity Equation. II: Numerical Results. Quart. J. Royal Meteor. Soc. 1987, 113, $1329-1347$.

Courtier, P.; Thépaut, J. N.; Hollingsworth A. A strategy for operational implementation of 4D-Var, using an incremental approach. Q. J. Roy. Meteor. Soc. 1994, 120, 1367-1387.

Doswell, C. A.; Flueck, J. A. Forecasting and Verifying in a Field Research Project: DOPLIGHT '87. Wea. Forecasting 1989, 4, 97-109.

Evensen, G. Sequential data assimilation with a nonlinear quasi-geostrophic model using Monte Carlo methods to forecast error statistics. J. Geophys. Res. 1994, 99, 10143-10162.

Findlater, J.; Roach, W. T.; McHugh, B. C. The haar of north-east Scotland. Quart. J. Roy. Meteor. Soc. 1989, $115,581-608$.

Fu, G.; Guo, J. T.; Xie, S. P.; Duan, Y. H.; Zhang M. G. Analysis and high-resolution modeling of a dense sea fog event over the Yellow Sea. Atmos. Res. 2006, 81, 292-303. 
Fu, G.; Li, P. Y.; Zhang, S. P.; Gao, S. H. A Brief Overview of the Sea Fog Study in China. Adv. Meteor. Sci. \& Tech. 2016, 6, 20-28. (in Chinese)

Gao, S. H.; Lin, H.; Shen, B.; Fu, G. A heavy sea fog event over the Yellow Sea in March 2005: Analysis and numerical modeling. Adv. Atmos. Sci. 2007, 24, 65-81.

Gao, S. H.; Qi, Y. L.; Zhang S. B.; Fu G. Initial conditions improvement of sea fog numerical modeling over the Yellow Sea by using cycling 3DVAR. Part I: WRF numerical experiments. J. Ocean Univ. China 2010, 40, 001-009. (in Chinese)

Gultepe, I.; Tardif, R.; Michaelides, S. C.; Cermak, J.; Bott, A.; Bendix, J.; Müller, M. D.; Pagowski, M.; Hansen, B.; Ellrod, G.; Jacobs, W.; Toth, G.; Cober, S. G. Fog research: A review of past achievements and future perspectives. Pure Appl. Geophys. 2007, 164, 1121-1159.

Hamill, T. M.; Snyder C. A hybrid ensemble Kalman filter-3D variational analysis scheme. Mon. Wea. Rev. 2000, 128, 2905-2919.

Hong, S. Y.; Lim, K. S.; Kim, J. H.; Lim, J. O. J.; Dudhia, J. The WRF single-moment 6-class microphysics scheme (WSM6). J. Korean Meteor. Soc. 2006, 42, 129-151.

Iacono, M. J.; Delamere, J. S.; Mlawer, E. J.; Shephard, M. W.; Clough, S. A.; Collins, W. D. Radiative forcing by long-lived greenhouse gases: Calculations with the AER radiative transfer models. $J$. Geophys. Res. 2008, 113, D13103.

Kain, J. S.; Fritsch, J. M. A one-dimensional entraining/detraining plume model and its application in convective parameterization. J. Atmos. Sci. 1990, 47, 2784-2802.

Koračin, D.; Dorman, C. E. Marine Fog: Challenges and Advancements in Observations, Modeling, and Forecasting, 1st ed.; Springer International Publishing: New York, USA, 2017; pp. 1-6.

Koračin, D.; Businger J. A.; Dorman C. E.; Lewis J. M. Formation, evolution, and dissipation of coastal sea fog. Bound. Layer Meteor. 2005, 117, 447-478.

Koračin, D.; Leipper D. F.; Lewis J. M. Modeling sea fog on the U.S. California coast during a hot spell event. Geofizika 2005, 22, 59-82. 
Koračin, D.; Lewis J.; Thompson W. T.; Dorman C. E.; Businger J. A. Transition of stratus into fog along the California coast: Observation and modeling. J. Atmos. Sci. 2001, 58, 1714-1731.

Lewis, J. M.; Koračin, D.; Rabin, R.; Businger J. Sea fog off the California coast: viewed in the context of transient weather systems. J. Geophys. Res. 2003, 108, 4457.

Li, R.; Gao S. H.; Wang Y. M. Numerical study on direct assimilation of satellite radiances for sea fog over the Yellow Sea. J. Ocean Univ. China 2012, 42, 10-20. (in Chinese)

Lin, Y. L.; Farley, R. D.; Oriville, H. D. Bulk parameterization of the snow field in a cloud model. $J$. Climate Appl. Meteor. 1983, 22, 1065-1092.

Liu, Y. D.; Ren, J. P.; Zhou X. The impact of assimilating sea surface wind aboard quikSCAT on sea fog simulation. J. Appl. Meteor. Sci. 2011, 22, 472-481. (in Chinese)

Lu, X.; Gao, S. H.; Rao, L. J.; Wang, Y. M. Sensitivity study of WRF parameterization schemes for the spring sea fog in the Yellow Sea. J. Appl. Meteor. Sci. 2014, 25, 312-320. (in Chinease)

Lu, X.; Wang, X. G.; Li, Y. Z.; Ma, X. L. GSI-based ensemble-variational hybrid data assimilation for HWRF for hurricane initialization and prediction: impact of various error covariances for airborne radar observation assimilation. Quart. J. Royal Meteor. Soc. 2017, 143, 223-239.

Nicholls, S. The dynamics of stratocumulus: Aircraft observation and comparison with a mixed layer model. Quart. J. Roy. Meteor. Soc. 1984, 110, 783-820.

Parrish, D. F.; Derber, J. C. The National Meteorological Center's spectral statistical-interpolation analysis system. Mon. Wea. Rev. 1992, 120, 1747-1763.

Poterjoy, J.; Zhang, F. Intercomparison and Coupling of Ensemble and Four-Dimensional Variational Data Assimilation Methods for the Analysis and Forecasting of Hurricane Karl (2010). Mon. Wea. Rev. 2014, 142, 3347-3364.

Shao, H.; Derber, J.; Huang, X. Y.; Hu, M.; Newman, K.; Stark, D.; Lueken, M.; Zhou C.; Nance, L.; Kuo, Y. H.; Brown, B. Bridging Research to Operations Transitions: Status and Plans of Community GSI. Bull. Amer. Meteor. Soc. 2016, 97, 1427-1440. 
Shen, F. F.; Min, J. Z.; Xu, D. M. Assimilation of radar radial velocity data with the WRF Hybrid ETKF-3DVAR system for the prediction of Hurricane Ike (2008). Atmos. Res. 2016. 169, 127138.

Skamarock, W. C.; Klemp, J. B.; Dudhia J.; Gill, D. O.; Barker, D. M.; Duda, M. G.; Huang X. Y.; Wang W.; Powers J. G. A description of the Advanced Research WRF version 3. Available online: http://www2.mmm.ucar.edu/wrf/users/docs/arw_v3.pdf (accessed in June 2008).

Stoelinga, M. T.; Thomas, T. W. Nonhydrostatic, mesobeta-scale model simulations of cloud ceiling and visibility for an East Coast winter precipitation event. J. Appl. Meteor. 1999, 38, 385-403.

Wang, B. H. Sea Fog, 1st ed.; China Ocean Press: Beijing, China, 1985.

Talagrand, O.; Courtier, P. Variational Assimilation of Meteorological Observations With the Adjoint Vorticity Equation. I: Theory. Quart. J. Royal Meteor. Soc. 1987, 113, 1311-1328.

Wang, J. J.; Gao, X. Y.; Gao, S. H. Data assimilation experiments and formation mechanism study of a Yellow Sea fog event. J. Marine Meteor. 2017, 37, 42-53. (in Chinese)

Wang, X. G. Application of the WRF Hybrid ETKF-3DVAR Data Assimilation System for Hurricane Track Forecasts. Wea. Forecasting 2011, 26, 868-884.

Wang, X. G.; Barker, D. M.; Snyder, C.; Hamill, T. M. A hybrid ETKF-3DVAR data assimilation scheme for the WRF model. Part I: Observing system simulation experiment. Mon. Wea. Rev. 2008, 136, 5116-5131.

Wang, X. G.; Barker, D. M.; Snyder, C.; Hamill, T. M. A hybrid ETKF-3DVAR data assimilation scheme for the WRF model. Part II: Real observation experiments. Mon. Wea. Rev. 2008, 136, $5132-5147$.

Wang, Y. M.; Gao S. H. Assimilation of Doppler Radar radial velocity in Yellow Sea fog numerical modeling. J. Ocean Univ. China 2016, 46, 1-12. (in Chinese)

Wang, Y. M.; Gao, S. H.; Fu, G.; Sun, J. L.; Zhang, S. P. Assimilating MTSAT-derived humidity in nowcasting sea fog over the Yellow Sea. Wea. Forecasting 2014, 29, 205-225. 
Whitaker, J. S.; Hamill, T. M. Ensemble Data Assimilation without Perturbed Observations. Mon. Wea. Rev. 2002, 130, 1913-1924.

Yang, Y.; Gao, S. H. Analysis on the synoptic characteristics and inversion layer formation of the Yellow Sea fogs. J. Ocean Univ. China 2015, 45, 19-30. (in Chinese)

Yang, Y.; Gao, S. H. Sensitivity study of vertical resolution in WRF numerical simulation for sea fog over the Yellow Sea. Acta Meteor. Sinica 2016, 74, 974-998. (in Chinese)

Yuan, B.; Fei, J. F.; Wang, Y. F.; Lu, Q. 4DVAR numerical simulation analysis using ATOVS data and asymmetrical bogus data on landing typhoon Weipha. Meteor. Mon. 2010, 36, 13-20. (in Chinese)

Zhang, S. P.; Xie, S. P.; Liu, Q. Y.; Yang, Y. Q.; Wang, X. G.; Ren, Z. P. Seasonal variations of Yellow Sea fog: Observations and mechanisms. J. Climate 2009, 22, 6758-6772.

Zhou, B. B.; Du, J. Fog prediction from a multimodel mesoscale ensemble prediction system. Wea. Forecasting 2010, 25, 303-322. 